\begin{tabular}{|c|}
\hline XVIème CONGRES DE LA SOCIETE \\
D'ANDROLOGIE DE LANGUE FRANCAISE \\
Issy-les-Moulineaux 9 - 11 Décembre 1999 \\
RÉSUMÉS DES COMMUNICATIONS \\
ORALES ET AFFICHÉES
\end{tabular}




\section{GENETIQUE ET CYTOGENETIQUE}

Fréquence des microdélétions du chromosome $\mathrm{Y}$ chez des hommes infertiles et fertiles d'origine danoise.

C.KRAUSZ, E.RAJPERT-DE MEYTS, L.F.LARSEN. et al

Mosaïques germinales $46, \mathrm{XY} / 46, \mathrm{X} \operatorname{del}(\mathrm{Y})$ chez des hommes oligozoospermiques.

Délétions du locus $\mathrm{AzFa}$ dans le syndrome de Del Castillo.

Macroorchidisme et spermatogenèse dans le syndrome de l'X fragile. A.PAGES, A.GENTIL-PERRET, R.LEVY. et al

Recherche de microdélétions du bras long du chromosome Y chez 250 hommes infertiles. F.FELLMANN, O.BLAGOSKLONOVA, C.ROUX. et al

Augmentation du risque de fausse-couche avec l'âge du père et de la mère.

\section{SPERMATOGENESE}

Caractérisation et localisation des transcrits codant pour la protéine TRBP pendant la spermatogenèse humaine.

J.F.SIFFROI, A.PAWLAK, M.F.ALFONSI, G.GUELLAEN, J.P.DADOUNE

Une altération de la communication jonctionnelle et de la connexine 43

est-elle impliquée dans l'effet délétère de certains pesticides sur la reproduction mâle?

A propos de l'action du lindane sur la lignée sertolienne 42GPA9.

N. DEFAMIE, M.CLEMENT-DURAND, S.POGGIOLI. et al.

Régulation de la connexine 43 par les spermatides âgées dans le testicule de rat mature.

X.DECROUY, C.BATIAS, G.POINTIS. et al.

Effets de l'Androgen-Binding Protein (ABP) sur la maturation des spermatozoïdes in vitro. J.DELLA-MARIA, A.GERARD, G.L.HAMMOND. et al.

La FSH et la testostérone régulent la glutathion S-transferase $\alpha$ (GST $\alpha$ ) dans la cellule de Sertoli en culture primaire.

L.BENBRAHIM-TALLA, F.BOUSSOUAR, C.REY. et al.

Régulation du récepteur de la FSH par le TNF $\alpha$ dans la cellule de Sertoli porcine.

M.KADEM, M.BENAHMED, R.GRATTAROLI

L'apoptose des cellules germinales est liée à une spermatogenèse anormale et à une qualité moindre des embryons après ICSI.

I.VIRANT-KLUN, D.STIBLAR-MARTINCIC , B.ZORN. et al.

Augmentation de la température scrotale durant la conduite d'un véhicule.

L.BUJAN, M.DAUDIN, J.P.CHARLET. et al.

Induction d'une hypothermie scrotale intense lors de la radiothérapie ou de la

chimiothérapie : étude de faisabilité.

L.BUJAN, J.M.BACHAUD, M.DAUDIN et al.

\section{SPERMIOLOGIE}

Concentrations du malondialdéhyde spermatique au sein d'une cohorte d'hommes fertiles.

A.LAUDAT, K.LECOURBE, A.M.PALLUEL

Evaluation des différentes sous-populations de cellules germinales dans le sperme

humain par cytométrie en flux.

L.CORCIA, Y.LEVERGNE, D.KERBOEUF, et al.

Apport du spermogramme dans le dépistage du varicocèle chez l'homme infertile.

L.AMMAR-KESKES, A.SELLAMI-BEN-HAMIDA, D.LTAIEF. et al.

Délai nécessaire pour concevoir et caractéristiques spermatiques :

une étude transversale auprès de 928 couples européens fertiles. 


\section{ASSISTANCE MEDICALE A LA PROCREATION}

Morphologie des spermatozoïdes migrés et résultats des inséminations intrautérines avec sperme de conjoint.

M.LAZREK, B.MARTIN-PONT, A.TEMSTET. et al.

Influence de l'étiologie de l'azoospermie dans les résultats biologiques et cliniques en ICSI?

F.GUERIF, C.BARTHELEMY, J.POINDRON. et al.

Fécondation assistée (ICSI) avec sperme testiculaire frais ou décongelé dans des dysgénésies gonadiques pures de Klinefelter.

Y.SOFFER, S.FRIEDLER, A.RAZIEL. et al.

F.ARNAL, T.ANABURY.

Autoconservation pour cancer testiculaire. Analyse rétrospective sur 20 ans (1979-1989).

C.BARTHELEMY, F.GUERIF, D.ROYERE, J.LANSAC.

Quel est l'apport de l'ICSI après paucifécondation en F.I.V. classique?

108

J.M. GRILLO, O. PAULMYER-LACROIX, J.BALZANO. et al.

Représentation des risques liés aux techniques d'assistance médicale à la procréation et comportement des médecins face aux situations d'infertilité. Etude préliminaire.

Apport respectif de la stimulation mécanique et de la chirurgie pour la conservation de spermatozoïdes et l'AMP chez le paraplégique.

N.FRANCOIS, F.KABOUB, J.C.JUILLARD, et al.

L'activité fusiogénique des spermatozoïdes humains après irradiation au laser

HENE à faible énergie (LFE).

Y.SOFFER, A.RAZIEL, A.UMANSKI et al.

Les auto-anticorps IgA et IgG fixés sur les spermatozoïdes perturbent leur attache à la zone pellucide mais non leur fusion avec l'oolème.

Y.SOFFER, A.RAZIEL, A.UMANSKI et al.

Intérêt du traitement du syndrome inflammatoire génital masculin avant AMP ?

A l'ère de l'injection intra-cytoplasmique de spermatozoïde, nouvel algorithme dans l'évaluation et le traitement des azoospermies.

\section{STERILITE}

Profil immunologique des patients consultant pour infertilité.

M.AJINA, N.CHAKROUN, H.HICHRI. et al.

Pesticides et fertilité : résultats d'une recherche épidémiologique menée auprès des viticulteurs alsaciens.

A.CLAVERT, B.DUCOT, A.SCHWEITZER. et al.

\section{CANCER}

Risque de deuxième cancer non germinal après traitement d'un séminome testiculaire de stade I-II. I.LATORZEFF, M.SOULIE, F.BERTHIER. et al.

Intérêt de l'échographie scrotale chez les patients infertiles aux antécédents de cryptorchidie : étude prospective de 147 cas.

J.P.GRAZIANA, J.M.RIGOT, Ph.MAHE. et al.

\section{SEXOLOGIE}

Traitement pharmacologique des troubles de l'éjaculation. Mise au point et analyse critique de la littérature. 


\section{GENETIQUE}

\section{La fréquence des microdélétions du chromo- some y chez des hommes infertiles et fertiles d'origine danoise.}

\section{Mosaïques germinales 46,xy/46,xdel(y) chez des hommes oligozoospermiques}

\section{LE BOURHIS., J.P. SIFFROI, J.P. DADOUNE}

Laboratoire d'Histologie, Biologie de la Reproduction et Cytogénétique, Hôpital Tenon, Paris.

Les microdélétions du chromosome $\mathrm{Y}$ peuvent être à l'origine d'une infertilité masculine. De nombreux travaux ont en effet montré le rôle important des gènes constituant le facteur AZF situé sur le bras long de l'Y au cours de la spermatogenèse. En 1996, Kent-First a mis en évidence une fréquence élevée (2/32) de délétions de l'Y chez des garçons nés par ICSI de pères oligozoospermiques non délétés. Ces résultats suggèrent l'existence de mosaïques somatiques et/ou germinales $46, \mathrm{Xy} / 46, \mathrm{Xdel}(\mathrm{y})$ chez ces pères.

Pour vérifier cette hypothèse, nous avons tout d'abord recherché par PCR, grâce à 10 séquences uniques (STS), des microdélétions de l'Y dans une série de 181 patients azoospermiques ou oligozoospermiques. Parmi eux, 47 ont fait l'objet d'une analyse en F.I.S.H. à l'aide d'une sonde cosmidique contenant la séquence du gène $\mathrm{DAZ}$, sur cellules somatiques et germinales.

Il a été mis en évidence une microdélétion dans 5,53 $\%$ des cas. Celle-ci concernait soit le locus AZFb, soit le locus AZFc. L'analyse par F.I.S.H. n'a révélé aucune délétion en mosaïque au niveau somatique. Chez 2 patients présentant une oligozoospermie sévère, avec absence de microdélétion par PCR, une mosaïque germinale $46, \mathrm{Xy} / 46, \mathrm{Xdel}(\mathrm{y})$ faible $(1,97 \%$ et $4,13 \%$ de spermatozoïdes porteurs d'un $Y$ délété) a pu être détectée.

Ces résultats montrent l'importance de la recherche systématique de ce type de délétions chez les hommes infertiles, candidats à la procréation médicalement assistée. La présence de mosaïques est une première étape dans la compréhension de certains cas d'infertilité idiopathique et pourrait aussi expliquer la fréquence élevée de délétions homogènes retrouvées chez les garçons nés par ICSI. Cependant la fréquence faible $(4,3 \%)$ de ces mosaïques conduit à postuler la présence d'autres gènes impliqués dans les infertilités de type oligozoospermie sévère ou azoospermie sécrétoire. danoise par comparaison avec d'autres populatio européennes comme la population finlandaise. 


\section{Délétions du locus azfa dans le syndrome de Del Castillo}

\section{O. BLAGOSKLONOVA1, F. FELLMANN2, C. ROUX2, M-C. CLAVEQUIN2, J-L. BRESSON2}

\author{
1 - Laboratoire d'Histologie - Embryologie- \\ Cytogénétique CNRS UPRESA 6025, Faculté de \\ Médecine. 2 - Service de Cytogénétique- \\ Immunocytologie-Biologie du Développement et de la \\ Reproduction, CHU. Place Saint-Jacques, 25030 \\ Besançon Cedex.
}

La recherche de corrélations génotype-phénotype dans les cas de microdélétions de la région AZF est difficile, notamment en raison du nombre limité d'investigations testiculaires à visée histologique.

Une démarche rétrospective, utilisant l'ADN extrait à partir de matériel testiculaire histologiquement caractérisé d'anciens prélèvements biopsiques fixés au Bouin et inclus en paraffine a été testée pour tenter de détecter des microdélétions Yq11.

Trente cinq échantillons datant de 1 à 30 ans ont été sélectionnés : 22 agénésies de la lignée germinale (syndrome de Del Castillo) et 14 biopsies présentant un arrêt de maturation au stade de Spermatocyte-I. Deux marqueurs (DFFRY et DAZ) ont été testés dans ces deux groupes par la technique de Nested PCR.

Dans la série de 22 biopsies avec syndrome de Del Castillo nous avons mis en évidence $4(18,2 \%)$ délétions touchant la région $\mathrm{AZFa}$ et en particulier le gène DFFRY. Dans la deuxième série testée aucune délétion n'a été détectée.

La fréquence élevée $(18,2 \%)$ de délétions observée dans la série de Del Castillo tendrait à impliquer la perte de la région $\mathrm{AZFa}$ dans cette pathologie. L'absence de repérage de délétions dans la série de 14 biopsies présentant un blocage en méiose I, au delà du hasard de recrutement, pourrait signifier qu'une autre cause éventuellement génétique est à rechercher dans ces situations.

Cette démarche méthodologique paraît intéressante, car l'étude rétrospective permet d'effectuer une présélection du matériel sur des critères histologiques et de fournir un certain nombre d'éléments de réponse à des questions actuellement posées concernant le retentissement au niveau testiculaire de la pathologie moléculaire de l'Y.

\section{Macroorchidisme et spermatogenèse dans le syndrome de l'x fragile}

\section{A. PAGES, A.GENTIL-PERRET, R.LEVY, CARMAND, J. JOSTAIN}
Service d'Urologie-Andrologie, Hôpital Nord. Saint Etienne

Le syndrome de l'X fragile est lié à l'expansion d'une séquence répétitive de triplets CGG dans la région 5 du gène FMR- 1 . Il en résulte l'absence de production de la protéine FMRp par blocage de la transcription du gène FMRI. Nous rapportons une étude hormonale, histologique et immunohistochimique sur un cas.

Notre observation semble confirmer l'explication du macroorchidisme par l'existence d'une hyperplasie du tissu interstitiel, d'un épaississement de la membrane basale péritubulaire et d'une augmentation du diamètre externe des tubes séminiferes sans anomalie morphologique des cellules de Leydig ou des cellules de Sertoli.

La spermatogenèse était normale. La négativité des ACAS sériques et la discrétion de 1 'œdème rendent peu probable le rôle de l'hyperpression péritubulaire évoqué pour des lésions semblables chez les vasectomisés.

Le rôle de FMRp dans la spermatogenèse reste controversé. Les immunomarquages semblent confirmer que la mutation complète est absente des cellules germinales soit parce que celle-ci pourrait empêcher la survie des cellules germinales ou parce que l'expression des triplets serait un événement post-zygotique épargnant la lignée germinale.

\section{Recherche de microdélétions du bras long du chromosome y chez 250 hommes infertiles}

\author{
F. FELLMANN 1-2, O. BLAGOSKLONOVA2, \\ C. ROUX 1-2, M.C. CLAVEQUIN 1-2, \\ H. BITTARD 3, J.L. BRESSON1-2
}

1-Service de Cytogénétique - Immunocytologie - Biologie du Développement et de la Reproduction, CHU 2 -

Laboratoire dHistologie - Embryologie- Cytogénétique

CNRS-UPRESA 6025, Faculté de Médecine 3 - Service

$d^{\prime}$ Urologie - Andrologie, CHU, Place Saint-Jacques,

25030 Besançon 
$\mathrm{Au}$ cours des 6 dernières années, plusieurs gènes ont été identifiés dans la partie euchromatique du bras long du chromosome Y, dont l'implication dans la spermatogenèse est actuellement reconnue. Le locus AZF (Azoospermia Factor) comporte quatre sous-régions dénommées $\mathrm{AZFa}, \mathrm{b}$, c et $\mathrm{d}$, au niveau desquels des gènes sont localisés, dont l'expression est le plus souvent exclusivement testiculaire et dont la perte est généralement associée à une azoosperrnie ou à une oligozoospermie sévère d'origine sécrétoire.

La possibilité de rechercher des microdélétions emportant un ou plusieurs de ces gènes utilisant la technique de PCR pour l'amplification de séquences connues et localisées sur le bras long de l'Y a permis de montrer qu'un certain nombre d'infertilités masculines jusqu'alors qualifiées d'idiopathiques avaient une origine génétique identifiable de façon relativement simple.

Notre étude a concerné 250 hommes consultant dans l'Unité de Biologie de la Reproduction pour infertilité au cours des trois dernières années. Une période initiale d'évaluation de la fréquence des microdélétions de la région $\mathrm{Yq} 11.23$, utilisant 24 marqueurs localisés dans les régions AZFa, b et c, dans une population de 130 patients présentant des troubles variés de la spermatogenèse a permis d'identifier 6 délétions $[6 / 130=4,6 \%]$, dont l'une était cytogénétiquement visible et dont les autres impliquaient principalement la région $\mathrm{AZFc}$ (limitées à un seul marqueur dans 2 cas, posant le problème de la signification fonctionnelle de telles observations). Ces microdélétions ont toutes été mises en évidence dans le groupe des 75 hommes présentant une azoospermie ou une oligozoospermie sévère de type sécrétoire (moins de $2.10^{6}$ spermatozoïdes $/ \mathrm{ml}$ ), soit une incidence dans ce groupe de $6 / 75=8 \%$.

En fonction de ces résultats, et des données convergentes de la littérature, nous avons donc décidé pour permettre une utilisation en routine de ces tests génétiques de limiter la recherche de microdélétions aux cas d'azoospermie ou d'oligozoospermie sévère, en limitant également le nombre des marqueurs de l'Y testés. L'étude de 120 patients supplémentaires répondant à ces critères a permis de détecter 5 nouvelles microdélétions qui, fait intéressant, touchent dans 3 cas la région AZFb (famille des gènes $\mathrm{RBM}$ ) et dans un cas la région $\mathrm{AZFa}$ (gène DFFRY), régions beaucoup plus rarement impliquées que la région des gènes $\mathrm{DAZ}$ en $\mathrm{AZFc}$.

La recherche de microdélétions de l'Y apparaît donc une analyse applicable en routine au cours du bilan de l'infertilité masculine, susceptible de fournir dans un certain nombre de cas une étiologie aux troubles de la spermatogenèse et permettant un conseil génétique. Les données recueillies au cours de telles analyses prospectives sont l'occasion par ailleurs de progresser dans les corrélations phénotype/génotype, encore largement discutées à l'heure actuelle.

\section{Augmentation du risque de fausse-couche avec l'âge du père et de la mère}

\section{E. DE LA ROCHEBROCHARD, P. THONNEAU}

Groupe de recherche sur la fertilité humaine, Service d'Urologie Andrologie, Hôpital La Grave, 31012 Toulouse, France

Il est assez bien établi que le risque de faussecouche augmente avec l'âge maternel. Toutefois très peu d'études ont été consacrées au rôle de l'âge du père sur l'issue de la conception.

Afin de prendre en considération l'âge des deux partenaires, femme et homme, dans le risque de fausse-couche, nous avons analysé l'issue de 3174 grossesses, collectées dans le cadre d'une étude européenne sur l'infécondité (European Study of Infertility and Subfecundity). L'âge du couple a été analysé et modélisé en une seule variable, 'couple jeune,' 'couple intermédiaire' et 'couple âgé'. L'analyse logistique a porté sur le risque de faussecouche en fonction de l'âge du couple, tout en tenant compte d'autres facteurs de risque connus.

Nos résultats montrent que si l'âge de l'homme est inférieur à 40 ans, le risque de fausse-couche est augmenté lorsque l'âge de la partenaire dépasse 35 ans. Lorsque l'âge de l'homme est supérieur à 40 ans, le risque de fausse-couche est significativement élevé dès que la partenaire a plus de 30 ans.

Cette étude précise, pour la première fois dans un modèle intégratif, l'influence directe de l'âge de l'homme sur le produit de conception, cela pour des tranches d'âge plutôt peu élevées : 30-35 ans, 35 40 ans. Ces données doivent amener les équipes médicales travaillant dans le domaine de la reproduction à informer les couples 'âgés', femme et homme, sur le risque de survenue de fausse-couche. 


\section{SPERMATOGENESE}

\section{Caractérisation et localisation des transcrits codant pour la protéine TRBP (TAR-RNA Binding Protein) pendant la spermatogenèse humaine}

\section{J.P. SIFFROI 1, A. PAWLAK 2, M.F.ALFONSI1, G. GUELLAEN 2, J.P.DADOUNE1}

1 : Laboratoire de Cytologie-Histologie, UFR

Biomédicale des Saints Pères, 45 Rue des Saints

Pères, 75270, Paris, France. 2 : Unité INSERM 99, Hôpital Henri Mondor, 94010, Créteil, France.

Mots clés: Spermiogenèse, Protamines, Régulation traductionnelle, Hybridation in situ, Microscopie électronique.

\section{Introduction}

Comme pour beaucoup de transcrits exprimés spécifiquement pendant la spermiogenèse, les ARNs messagers codant pour les protamines chez l'homme sont soumis à une régulation post-transcriptionnelle. En effet, leur traduction en protéine survient à la fin de la phase d'élongation des spermatides (stades 4-5 de la spermiogenèse) [6,5] alors même que leur transcription a débuté dès le stade des spermatides rondes [7]. Cette régulation implique des protéines spécifiques de liaison à l'ARN [8] reconnaissant des séquences spécifiques de la partie 3' non traduite (3' UTR) des transcrits. Chez des souris transgéniques possédant un gène " reporter " (hormone de croissance humaine), placé sous le contrôle du promoteur du gène de la protamine 1 murine, la synthèse de la protéine hGH n'a lieu dans les spermatides en élongation que lorsque les transcrits ont conservé les 62 nucléotides les plus distaux de la partie 3' UTR [1, 2].

Une des protéines de liaison à l'ARN responsable de cette régulation chez la souris est la protéine Prbp (Protamine-1 RNA Binding Protein) [4] dont l'analogue humain est la protéine TRBP [TAR (Trans Activation Responsive) RNA Binding Protein] connue jusqu'à présent pour son rôle dans l'activation du virus HIV [3]. Le but de ce travail a donc été de caractériser et de localiser les transcrits codant pour TRBP dans le testicule humain.

\section{Matériel et méthodes}

A partir d'un clone cDNA contenant un insert de 1020 paires de bases $(\mathrm{pb})$ codant pour TRBP, ont été préparées des sondes spécifiques soit par marquage de l'insert seul au [ $\alpha 32 \mathrm{P}]$ pour l'analyse des membranes de Northern blots, soit par transcription in vitro et marquage au [33 P] pour la synthèse de ribosondes sens et anti-sens et l'hybridation in situ en microscopie photonique, soit encore par amplification enzymatique (PCR) d'un fragment de $154 \mathrm{pb}$ avec marquage direct à la digoxigénine pour l'hybridation in situ en microscopie électronique.

La caractérisation des transcrits sur Northern blots a été réalisée par hybridation de la sonde marquée sur deux types de membranes du commerce (Clontech, USA) contenant des dépots d'ARNs extraits de différents tissus humains. La révélation du signal a été faite après 15 jours d'exposition.

Pour l'hybridation in situ, le matériel testiculaire a été obtenu à partir d'orchidectomies pratiquées pour cancer de la prostate chez des hommes âgés de 60 à 65 ans et n'ayant pas reçu de traitement préalable par chimio ou hormonothérapie. Pour la microscopie photonique, des coupes à congélation ont été hybridées avec les ribosondes sens et antisens marquées. Le signal a ensuite été révélé par autoradiographie au bout de 8 jours d'exposition. Une étude ultrastructurale quantitative a été réalisée par hybridation in situ en microscopie électronique avec révélation des hybrides par immunocytochimie-or colloïdal.

L'analyse quantitative a porté sur les spermatides divisées en trois groupes: $\mathrm{Sr}$ : spermatides rondes (stades 1-2) ; Sel 1 : spermatides en début de phase d'élongation (stades 3-4); Sel 2 : spermatides en fin de phase d'élongation (stades 5-6). Trente cellules de chaque groupe ont été comptées et la densité de particules d'or a ensuite été rapportée à une surface de $100 \mu 2$. L'étude de spermatogonies dans les mêmes conditions a servi de contrôle. Une analyse de variance (ANOVA) et le test de Scheffé ont été utilisés pour le traitement statistique des résultats.

\section{Résultats et discussion}

L'hybridation moléculaire sur Northern blots a révélé l'existence d'un transcrit majoritaire à $1,5 \mathrm{~kb}$ exprimé fortement dans le testicule mais retrouvé également, à un niveau plus faible, dans d'autres tissus comme le coeur, le placenta, le foie ou le pancréas. Deux autres transcrits mineurs, situés à 3,2 $\mathrm{kb}$ et $5,4 \mathrm{~kb}$, ont été détectés dans ces mêmes tissus. La taille et la distribution tissulaires des transcrits codant pour TRBP sont en accord avec les données obtenues chez la souris pour la protéine Prbp [4, 9]. Les transcrits mineurs observé à $3,2 \mathrm{~kb}$ et $5,4 \mathrm{~kb}$ ne représentent certainement que des formes non maturées de ces transcrits ou ne reflètent qu'une hybridation non spécifique des sondes utilisées. 
Sur les coupes à congélation, l'hybridation d'une sonde anti-sens marquée a montré une distribution des grains d'argent limitée aux spermatides en cours d'élongation et, parfois, à quelques spermatides rondes. L'hybridation de la sonde contrôle sens n'a donné qu'un très faible marquage non spécifique correspondant au bruit de fond. Cette distribution suggère fortement que la protéine TRBP est impliquée dans la régulation post-transcriptionnelle des transcrits codant pour les protamines.

A un niveau ultrastructural, la distribution des particules d'or colloïdal a montré que celles-ci étaient localisées dans le noyau et le cytoplasme des spermatides, sans association à un organite intracellulaire particulier. L'analyse quantitative a révélé des densités de marquage statistiquement différentes entre les trois groupes de spermatides (ANOVA, $p<0,0001$ ) (Figure 1).

TRBP2

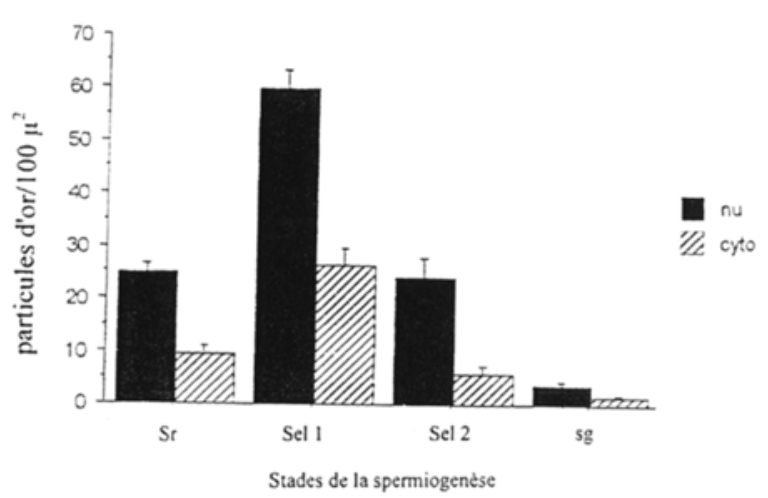

figure 1 : Evolution de la densité de marquage, exprimée en nombre de particule d'or colloüdal par $100 \mu 2$, des transcrits codant pour la protéine TRBP au cours de la spermiogenèse (SR: spermatides rondes; Sel1: spermatides en début de phase d'élongation; Sel2: spermatides en fin de phase d'élongation, Sg: spermatogonies).

Un marquage nucléaire significatif est observé dès le stade des spermatides rondes ( $\mathrm{Sr}$ ) par rapport aux spermatogonies servant de contrôle ( $\mathrm{p}<$ 0,0001). La densité de marquage nucléaire augmente ensuite considérablement dans les spermatides en début d'élongation (Sel 1) $(\mathrm{p}<0,0001)$ pour diminuer brutalement dans celles en fin de phase d'élongation (Sel 2) $(\mathbf{p}<0,0001)$ tout en restant à un niveau différent de celui des contrôles $(\mathrm{p}<0,0001$ ). Dans le cytoplasme, la densité de particules d'or a toujours été inférieure à celle observée dans le noyau et ce pour les trois groupes de spermatides étudiés $(p<0,0001)$. Dans le groupe $\mathrm{Sr}$, cette densité de marquage cytoplasmique est légèrement différente de celle des contrôles $(p=0,056)$ puis elle augmente fortement dans le groupe Sel 1 ( $p<$
0,0001 ) avant de diminuer de façon significative dans le groupe Sel $2(\mathrm{p}<0,0001)$ jusqu'à un niveau peu différent de celui des contrôles ( $p=0,051$ ). Ces données révèlent une concordance exacte entre le niveau maximum d'expression des transcrits de TRBP, aux stades 3-4 de la spermiogenèse, et le moment où les ARNs messagers codant pour la protamine HP1 commencent à disparaître, et donc à être traduits en protéine, comme cela a pu être montré dans une étude précédente [7].

En conclusion, le profil d'expression du gène codant pour la protéine TRBP humaine est en accord avec le rôle présumé de celle-ci dans la levée du blocage traductionnel des transcrits réprimés codant pour les protamines.

\section{Références}

1. BRAUN RE., PESCHON JJ., BEHRINGER RR., BRINSTER RL., PALMITER RD. Protamine 3'untranslated sequences regulate temporal translational control and subcellular localization of growth hormone in spermatids of transgenic mice. Genes Dev., 1989, $3: 793-802$.

2. BRAUN RE. Temporal translational regulation of the protamine 1 gene during mouse spermatogenesis. Enzymes, 1990, $44: 120-128$.

3. GATIGNOL A., BUCKLER-WHITE A., BERKHOUT B., JEANG KT. Characterization of a human TAR RNA-binding protein that activates the HIV-1 LTR. Science, 1991, 251: 1597-1600.

4. LEE K., FAJARDO MA., BRAUN RE. A testis cytoplasmic RNA-binding protein that has the properties of a translational repressor. Mol. Cell Biol., 1996, 16 : 3023-3034.

5. LESCOAT D., BLANCHARD Y., LAVAULT MT., QUERNEE D., LE LANNOU D. Ultrastructural and immunocytochemical study of $\mathrm{P} 1$ protamine localization in human testis. Andrologia, 1993, 25 : 93-99.

6. ROUX Ch., GUSSE M., CHEVAILLER Ph., DADOUNE JP. An antiserum against protamines for immunohistochemical studies of histone to protamine transition during human spermiogenesis. J. Reprod. Fertil., 1988, $82: 35-42$.

7. SIFFROI JP., ALFONSI MF., DADOUNE JP. Co-localization of HP1 and TP1 transcripts in human spermatids by double electron microscopy in situ hybridization. Int. J. Androl., 1999, 22 : 83-90.

8. VENABLES JP., EPERON IC. The roles of RNA-binding proteins in spermatogenesis and male infertility. Curr. Opin. Genet. Dev., 1999, 9 : 346-354.

9. ZHONG J., PETERS A., LEE K., BRAUN RE. A double-stranded RNA binding protein required for activation of repressed messages in mammalian germ cells. Nat. Genet., 1999, 22 : 171-174. 
Une altération de la communication jonctionnelle et de la connexine 43 est-elle impliquée dans l'effet délétère de certains pesticides sur la reproduction mâle?

à propos de l'action du lindane sur la lignée sertolienne 42gp,49

N DEFAMIE1, M. CLEMENT-DURAND1, S. POGGIOLI1, L. CRONIER1, A. MALASSINE2, D. SEGRETAIN1, P.FENICHEL1, G. POINTIS1

1 INSERM CJF 95104, Faculté de Médecine, Avenue de Valombrose, 06107 Nice 2 CNRS UNIR 65-58, Université de Poitiers

Le lindane ( $\mathrm{y}$-hexachlorocyclohexane, $\mathrm{HCH}$ ), pesticide largement utilisé, est connu pour ses effets neurotoxique, embryotoxique, hépatocarcinogène. Il exerce aussi des effets délétères sur la fonction de reproduction mâle par des mécanismes encore mal identifiés. Dans le présent travail, nous nous sommes proposés de montrer qu'une altération testiculaire de la communication jonctionnelle par gap junction (GJC) pourrait être une des conséquences des propriétés toxiques de l'HCH en utilisant comme modèle d'étude la lignée de cellules de Sertoli murine 42GPA9 qui exprime la connexine 43 (Cx 43), protéine constitutive des gap junctions (Bourdon et colt, Biol Reprod. 1998, 58, 591-599; Lablack et coll, Cell. Tissue Res. 1998, 294, 279287).

L'effet de l'HCH à des concentrations inférieures à $50 \mathrm{pM}$ qui n'affectent ni la viabilité ni la prolifération des cellules a été analysé au niveau des ARNm de la $\mathrm{Cx} 43$, de la protéine et de la fonctionnalité du couplage jonctionnel. Nos résultats montrent que l'HCH est capable d'inhiber totalement la GJC mesurée par gap FRAP. Cette altération ne semble pas être associée à une diminution du nombre des transcrits mesurés par RT-PCR semi quantitative et de la $\mathrm{Cx} 43$ quantifiée par Western blot. En revanche alors que la CX43 est localisée au niveau membranaire dans les cellules de contrôle, l'exposition à l'HCH, même pendant des temps très courts, amène à une délocalisation de la protéine immunodétectée dans le cytoplasme des cellules traitées. $\mathrm{La}$ localisation de la $\mathrm{Cx} 4,3$ est retrouvée par contre au niveau membranaire en cas d'inhibition de la voie de dégradation des protéasomes par ALLN (20mLM)

L'ensemble de ces observations suggère qu'un des effets toxiques du lindane sur la fonction testiculaire pourrait être médié par une altération de la communication jonctionnelle au sein de cet organe.

D.N. bénéficie d'une allocation de recherche de l'ADEME. Ce travail est soutenu par un contrat européen.
Régulation de la connexine 43 par les spermatides âgées dans le testicule de rat mature.

\section{DECROUY 1 C. BATIAS 1 G. POINTIS 2 , D. SEGRETAIN 1}

1 GECC, Histo-Embryologie, Université Paris V, 45 rue des St Pères, 75006 Paris. 2 CJF, INSERM 95/04.EA 1760. Faculté de Médecine. 06107 Nice

Les jonctions communicantes et leurs protéines constitutives, les connexines $(\mathrm{Cx})$ sont impliquées dans le maintien et le déroulement normal de la spermatogenèse. Dans le but d'étudier le rôle des cellules germinales dans la régulation de la connexine 43 , connexine majoritaire au sein des tubes séminiferes, deux approches différentes et complémentaires ont été développées. L'expression de la connexine 43 a été analysée par hybridation in-situ et par immunofluorescence indirecte.

La technique de transillumination développée par M. Parvinen (1990) permet d'isoler spécifiquement des tubes aux stades VII-VIII, moment de la spermiation., et aux stades LX--X, début de la phase d'élongation des spermatides. L'expression de la connexine 43 est plus faible dans les stades LX-X comparée aux stades VII-VIII chez les rats. Les tubes de stades LX-X ont été mis en culture avec des spermatozoïdes secondaires et des spermatides prélevés sur des tubes de stades VII-VIII. Le niveau d'expression de la connexine 43 observé dans ce cas est augmenté dans les tubes aux stades LX-X.

Une approche expérimentale qui permet une déplétion spécifique et séquentielle des cellules germinales dans les tubes séminiferres a été utilisée (exposition des testicules $15 \mathrm{~min}$. à $43^{\circ} \mathrm{C}$ ). Huit jours après l'exposition. les spermatides rondes et les spermatocytes pachytènes sont absents des tubes séminifères au stade VII alors que les spermatides allongées sont encore présentes. L'expression basale de la connexine 43 et de son messager est similaire à celle observée dans les tubes séminifêres contrôles. Par contre, vingt six jours après l'exposition, les spermatides âgées sont totalement ou partiellement déplétées dans les tubes séminifêres au stade VII et l'expression de la connexine 43 et de son messager est absente ou fortement diminuée dans ces tubes.

L'ensemble de ces résultats montre d'une part que les cellules germinales ont un rôle dans la régulation de l'expression de la connexine 43 dans les tubes séminiferes et d'autre part que seules les spermatides âgées contrôlent cette expression.

Parvinen M., Kangasniemi M., Kaipa A., Mali P., Toppari J., Huhtanierni L., (1990) Anat. Rec.., 227 : 62-76 Ce travail a été financé par l'ARC $\left(n^{\circ} 9880\right)$ 
Effets de l'androgen-binding protein (abp) sur la maturation des spermatides in vitro

J. DELLA MARIA 1, A. GERARD 1, J. L. COR-

DONNIER 1, G. L. HAMMOND 2, B. LEHEUP 1, H. GERARD 1

1 EA 2401 Génétique et Interactions Cellulaires en Reproduction, Département de Cytologie, Histologie et Embryologie, Faculté de Médecine, Nancy I, 54500 Vandoeuvre les Nancy, France

2 - Department of Obstetrics and Gynecology and Pharmacology and Toxicology, The University of Western Ontario, LRCC Cancer Research Laboratories, London, Ontario, Canada

Introduction-but: L'Androgen-Binding Protein sertolienne, liant avec haute affinité les stéroïdes, se fixe, puis est internalisée de façon spécifique par les cellules germinales via un mode d'endocytose récepteur médiée selon leur stade de maturation (Gérard et al., 1994; 1995). Des modifications du taux d'ABP sont associées à des perturbations de la spermiogenèse (Huang et al., 1992). Les spermatides expriment le gène codant pour la Transition Protein 1 (TP1) qui intervient dans la première étape de la maturation nucléaire du gamète définitif. Son expression, maximale aux stades VII et VIII du cycle de l'épithélium séminifêre (Mali et al., 1989) lorsque l'ABP est à son taux le plus élevé (Parvinen et al., 1982), présente une régulation à la fois transcriptionnelle et traductionnelle. Elle est supposée androgéno-dépendante (Sharpe et al., 1994).

Notre objectif est de vérifier si l'ABP recombinante de rat peut avoir un effet sur l'expression du gène de la TP1en présence ou non de stéroïdes dans un modèle de coculture.

Méthodes: Des cellules de Sertoli murines $\left(6.10^{4} / 0,3 \mathrm{ml} / \mathrm{cm} 2\right)$ produisant ou non de l'ABP recombinante de rat ont été cocultivées avec des fractions contenant $3.10^{6}$ spermatides (enrichies à $95 \%$ ) à $34^{\circ} \mathrm{C}$ et $5 \%$ de $\mathrm{CO} 2$ dans du milieu de culture DMEM-Ham F12 additionné de 0,65 \% de lactate et de $1 \%$ de pyruvate soit par contact direct entre les deux types cellulaires soit sans contacts cellulaires (séparées par une membrane microporeuse). D'autres cocultures ont été réalisées avec adjonction de stéroïdes $(50 \mathrm{ng} / \mathrm{ml}$ de testostérone ou d'œstradiol ; Sigma). Des cocultures avec des CHO produisant l'ABP recombinante de rat ont été réalisées comme contrôle de la spécificité testiculaire.

La viabilité, le nombre et l'adhérence des spermatides ont été évalués par des tests d'exclusion au Bleu Trypan et comptages à la cellule de Thomas après 1,3 ou 6 jours de coculture. Les ARN totaux ont alors été extraits à partir des spermatides grâce au Tri Reagent (Sigma) et utilisés à raison de 150 ng par échantillon pour des réactions de RT-PCR effectuées à l'aide des réactifs du kit " Titan One Tube RT-PCR " (Boehringer) et d'un couple d'amorces spécifiques du gène TP1 de rat (Weiss et al., 1998). Le séquençage des produits de RT-PCR a été réalisé selon la méthode de Sanger grâce aux réactifs du kit " ABI PRISM Dye Terminator Cycle Sequencing Ready Reastion "(Perkin Elmer).

Résultats: 1) Effets significativement positifs sur : la viabilité des spermatides : $72 \pm 2 \%$ à $3 \mathrm{j}$ et $67 \pm$ $1 \%$ à $6 \mathrm{j}$ en présence d'ABP seule versus $68 \pm 1 \%$ et $60 \pm 2 \%$ sans $\mathrm{ABP}$; le maintien du nombre total de spermatides : $78 \pm 1 \%$ à $3 \mathrm{j}$ et $67 \pm 1 \%$ à $6 \mathrm{j}$ en présence d'ABP seule versus $68 \pm 1 \%$ et $60 \pm 3 \%$ à 6 sans ABP ; le nombre de spermatides adhérentes aux cellules de Sertoli produisant de l'ABP : $76 \pm 2$ $\% 3 \mathrm{j}$ et $73 \pm 1 \%$ à $6 \mathrm{j}$ versus $71 \pm 1 \%$ et $67 \pm 2 \%$ avec des cellules de Sertoli ne produisant pas d'ABP.

2) Obtention dans toutes les conditions de coculture, et à partir d'ARN extrait de tissu testiculaire de rat adulte utilisé comme contrôle positif, d'un fragment de 175 pb caractérisé par séquençage comme le produit de l'amplification de la séquence du messager TP1. Effet activateur de l'ABP sur la transcription du gène codant pour la TP1. L'adjonction de stéroïdes réduit l'effet stimulateur de cette transcription. Les contacts directs entre les cellules produisant de l'ABP et les spermatides amplifient l'effet activateur de la transcription.

Discussion-conclusion: Les conditions expérimentales de coculture choisies permettent le maintien d'un grand nombre de spermatides vivantes capables de réponse aux modifications environnementales et révèlent l'effet positif de l'ABP sur la viabilité et la stimulation de l'expression du gène TP1. Cet effet activateur est modulé par la présence des stéroïdes. Il est plus marqué dans le cas d'ABP sécrétée par les cellules de Sertoli que dans le cas d'ABP sécrétée par les cellules extra-testiculaires (CHO) ce qui suggère un effet tissu spécifique.

\section{La FSH et la testostérone régulent la gluta- thion s-transférase $\alpha$ (gst $\alpha$ ) dans la cellule de Sertoli en culture primaire}

L BENBRAHIM-TALLAA., F BOUSSOUAR.,
C REY., E TABONE., F HATEY, M BENAHMED

INSERM U407 Faculté de médecine Lyon-Sud BPI 2 F-69921 Oullins Cedex, France. 
L'induction des enzymes de la phase Il de détoxification est le mécanisme majeur de protection des cellules contre les substances toxiques et les effets des radiations. Les molécules responsables de dommages dûs a une agression chimique ou à des radiations sont les radicaux libres. Une implication potentielle d'un défaut de détoxification à l'origine d'infertilité nous ont amenés à examiner la régulation d'une enzyme de la phase I de détoxification, la glutathion S-transferase $(\alpha(\mathrm{GST} \alpha)$, par les deux hormones clef de la spermatogenèse (FSH, testostérone) et par un facteur local ( $\mathrm{TNF} \alpha$ ) dans la cellule de Sertoli en culture primaire. La GST $\alpha$ protège les cellules contre les substances toxiques par sa capacité à catalyser la conjugaison du glutathion réduit avec des substances électrophiles variées. Les résultats obtenus indiquent que la FSH stimule l'expression de l'ARNm de la CST $\alpha$ de façon dose $(\mathrm{ED} 50=18,5 \mathrm{ng} / \mathrm{ml})$ dépendante. Cette stimulation augmente en fonction du temps avec un effet dès $4 \mathrm{~h}$ de traitement et un maximal atteint après $48 \mathrm{~h}$ de traitement (3fois -, $\mathrm{P}<0.001$ ). Le traitement par la testostérone montre également une stimulation dose $(\mathrm{ED} 50=1,4 \mathrm{ng} / \mathrm{ml})$ et temps dépendante avec un maximum après $16 \mathrm{~h}$ d'exposition (2fois; $\mathrm{P}<0.05$ ). Le TNF $\alpha$, au contraire, inhibe l'expression des ARNm de la GST $\alpha$ de façon dose (15fois , $\mathrm{P}<0.001$ ) et temps ( 3 fois $\mathrm{P}<0.001$ ) dépendante avec un effet maximal à $48 \mathrm{~h}$. L'étude de la protéine (GST $\alpha)$ montre que celle-ci augmente parallèlement dans les cellules de Sertoli traitées par FSH, testostérone et qu'elle diminue en présence de TNF $\alpha$ L'ARNm de la GST $\alpha$ reste stable après le traitement par la FSH mais pas après traitement par la testostérone. En somme, ces observations suggèrent que le rôle clef de la FSH et de la testostérone dans la spermatogenèse pourrait passer par le biais d'une augmentation des capacités de défense de la cellule.

\section{Régulation de l'expression du récepteur de la FSH par le TNF $\alpha$ dans la cellule de Sertoli porcine.}

\section{KADEM, M BENAHMED, R GRATAROLI}

\section{INSERM U407, Faculté de Médecine Lyon-Sud.} B.P. 12, F-69921 Oullins Cedex

Les cellules de Sertoli jouent un rôle important dans le déroulement normal de la spermatogenèse. Par l'intermédiaire de son récepteur, la FS régule de nombreuses fonctions de la cellule de Sertoli ainsi que la sécrétion de plusieurs protéines, substrats énergétiques, facteurs de croissance et sté- roïdes (DHT, androsténediones, ou $17 \beta$-estradiol). Le TNF $\alpha$ (essentiellement produit par les cellules germinales) semble jouer un rôle prépondérant dans le contrôle local de la gamétogenèse. L'action antagoniste de cette cytokine sur la conversion de la testostérone en $17 ß$-estradiol par l'aromatase en présence de FSH, nous a conduits à étudier le rôle $d u \mathrm{TNF} \alpha$ sur la régulation de l'expression de l'ARN messager du récepteur de la FSH et sur la capacité de fixation de la FSH sur son récepteur.

Les techniques utilisées sont le Northern blot, la liaison de la FSH à son récepteur (binding) et le dosage radio- immunologique de l'activité aromatase.

Résultats 1 - Le TNFa ( 10ng/ml) diminue l'expression de l'ARN messager du récepteur de la FSH à partir de $6 \mathrm{~h}(-37 \%)$ et atteint très rapidement un plateau de $90 \%$ d'inhibition à partir de $12 \mathrm{~h}$ (jusqu'à $48 \mathrm{~h})$.

2- En présence de $\mathrm{TNF} \alpha(10 \mathrm{ng} / \mathrm{ml})$, la capacité de fixation de la FSH $(0,25 \mathrm{pg} / \mathrm{ml})$ à son récepteur diminue de $28 \%$ à partir de $12 \mathrm{~h}$ pour atteindre un maximum de 40 à $50 \%$ d'inhibition à $24 \mathrm{~h}$ qui se maintient à $48 \mathrm{~h}$.

3- En présence de FSH $(0,25 \mathrm{pg} / \mathrm{ml})$ et de TNF $\alpha$ (10 $\mathrm{ng} / \mathrm{ml}$ ), la diminution de 40 à $50 \%$ de l'activité aromatase est observée à $48 \mathrm{~h}$ c'est-à--dire $36 \mathrm{~h}$ après le maximum d'inhibition de l'expression du récepteur de la FSH et $24 \mathrm{~h}$ après le maximum d'inhibition de la capacité de liaison de la FSH à son récepteur.

Conclusion L'intérêt de ce travail a été de montrer que le $\mathrm{TNFa}$, joue un rôle régulateur certain au niveau de l'action de la FSH sur la cellule de Sertoli -en diminuant l'expression de l'ARN messager du récepteur sertolien de la FSH

-en diminuant la capacité de fixation de la FSH à son récepteur

-en confirmant un antagonisme sur l'activité aromatase stimulée par la FSH

Des expériences complémentaires sont nécessaires pour démontrer si ces résultats expérimentaux sont effectivement reliés.

\section{L'apoptose des cellules germinales est liée à une spermatogenèse anormale et à une qualité moindre des embryons après ICSI}

I.VIRANT-KLUN1, D. STIBLAR-MARTINCIC2, B. ZOM1, J. SINKOVEC1, T. TOMAZEVIC1, H. MEDF-N-VRTOVEC1 
1 Centre d'Andrologie, Service de gynécologie obstétrique, Centre clinique universitaire de Ljubljana

2 Service dHisto-Embryologie, Faculté de

Médecine, Université de Ljubljana, Slovénie

Introduction: L'apoptose ou mort cellulaire programmée peut être définie comme l'induction et la réalisation d'une série parfaitement ordonnée d'événements discrets qui conduisent à la mort de la cellule et à sa destruction. La condensation chromatinienne et la fragmentation de l'ADN surviennent très tôt dans l'apoptose et sont les principales caractéristiques de ce processus. L'apoptose a un rôle essentiel dans le contrôle du nombre de cellules germinales testiculaires. C'est un phénomène normal dans le testicule humain mais il peut être augmenté par le manque en hormones testiculaires, en particulier gonadotrophines et testostérone, la cryptorchidie, les substances toxiques, la chimiothérapie et la radiothérapie, toutes notions bien documentées sur les modèles animaux.

Les buts de l'étude étaient: 1) de confirmer la présence de l'apoptose et d'en déterminer la fréquence au niveau de fragments biopsiques testiculaires en utilisant la méthode TUNEL (terminaldeoxynucleotidyl-transferase mediated d-UTP-biotin nick-end labelling) qui révèle la fragmentation de l'ADN apoptotique, 2) de chercher les facteurs qui agissent sur l'apoptose au niveau du testicule humain et 3) d'évaluer les effets de l'apoptose des cellules germinales sur les résultats de la fécondation in vitro (FIV).

Matériel et méthodes : Le tissu testiculaire a été obtenu par biopsie testiculaire chez 34 patients infertiles soit azoospermiques, souffrant d'anéjaculation ou oligoasthénotératozoospermies sévères. Chaque échantillon de tissu a fait l'objet de recherche extemporanée de spermatozoïdes, d'une analyse histologique standard et d'une détection de cellules germinales apoptotiques par la méthode TUNEL. Les cellules apoptotiques ont été identifiées microscopiquement par leur couleur marron sombre. La fréquence des cellules apoptotiques a été exprimée par un index d'apoptose (AI) qui est le nombre de cellules apoptotiques par 1000 cellules germinales ou de Sertoli. Le reste de l'échantillon a été congelé pour être utilisé a distance en FIV. 16 cycles de FIV avec injection intracytoplasmique de spermatozoïde (ICSI) ont été tentés avec spermatozoïdes décongelés.

Résultats et conclusion : L'apoptose des cellules germinales a été détectée dans $25(73 \%)$ fragments testiculaires. L'index d'apoptose a été de $1,4 \pm 1,2 \%$, s'étalant entre 0 et $13,7 \%$. Chez les patients avec syndrome des cellules de Sertoli uniques, il n'y avait pas d'apoptose. Chez ceux avec hypoplasie germinale et arrêt de la maturation, l'AI était significativement augmenté par rapport a ceux avec spermatogenèse normale $(2,3 / 2,4$ vs $0.9, \mathrm{p}<0,05)$. Il y avait une corrélation négative entre le niveau de l'AI et le taux de la FSH sérique ( $\mathrm{r}=0,5089$. $\mathrm{p}<0.05$ ) et une corrélation positive entre l'AI et le taux de l'inhibine B plasmatique ( $r-0.6179$, $\mathrm{p}<0.05$ ). Après ICSI avec sperme testiculaire décongelé, il y avait une corrélation positive entre l'AI et une qualité moindre des embryons, qui montrent plus de $30 \%$ de fragmentation $(r=0,5683, p<0.05)$. Par ailleurs, il y avait une corrélation négative entre le taux de l'AI et l'obtention d'une grossesse ( $\mathrm{r}$ $=0.5819, \mathrm{p}<0.05$ ). L'apoptose des cellules germinales testiculaires est impliquée dans la spermatogenèse anormale et le mauvais développement embryonnaire chez l'homme infertile.

\section{Augmentation de la température scrotale durant la conduite d'un véhicule}

\author{
L. BUJAN, M. DAUDIN, J.P. CHARLET, \\ P. THONNEAU, R. MIEUSSET
}

Groupe de Recherche sur la Fertilité Humaine, CSM-CECOS Service d'Uro-Andrologie CHU La Grave Toulouse, France

INTRODUCTION: Deux études récentes font apparaître la position assise prolongée comme un facteur de risque pour la fertilité chez l'homme: 1) augmentation significative du délai nécessaire pour concevoir si l'homme est assis plus de 3 heures dans un véhicule par rapport à des hommes non soumis à cette exposition (Thonneau 1996), 2) augmentation du pourcentage de spermatozoïdes anormaux chez les chauffeurs de taxi comparés à un groupe témoin (Figa-Talamanca 1996). Le testicule étant un organe thermo-dépendant (Mieusset and Bujan 1995) l'hypothèse d'une augmentation de la température a été évoquée sans être démontrée. Cette étude montre pour la première fois les effets de la position assise durant la conduite sur la température scrotale.

METHODES : Chez neuf hommes, volontaires sains, la température scrotale est enregistrée, toute les 2-minutes, grâce à des thermocouples et une centrale portable, lors de la marche (40 minutes) puis lors de la conduite d'un véhicule durant 160 minutes.

RESULTATS : La température scrotale moyenne $\pm \mathrm{SD}$, augmente, significativement à gauche et à 
droite, de $34,5 \pm 1,1 \mathrm{C}^{\circ}$ et $34,2 \pm 0.8^{\circ} \mathrm{C}$ durant la marche, à $36,2 \pm 0,8^{\circ} \mathrm{C}$ et $36,4 \pm 0,5^{\circ} \mathrm{C}$ après avoir conduit deux heures $\mathrm{p}<0,0001$.

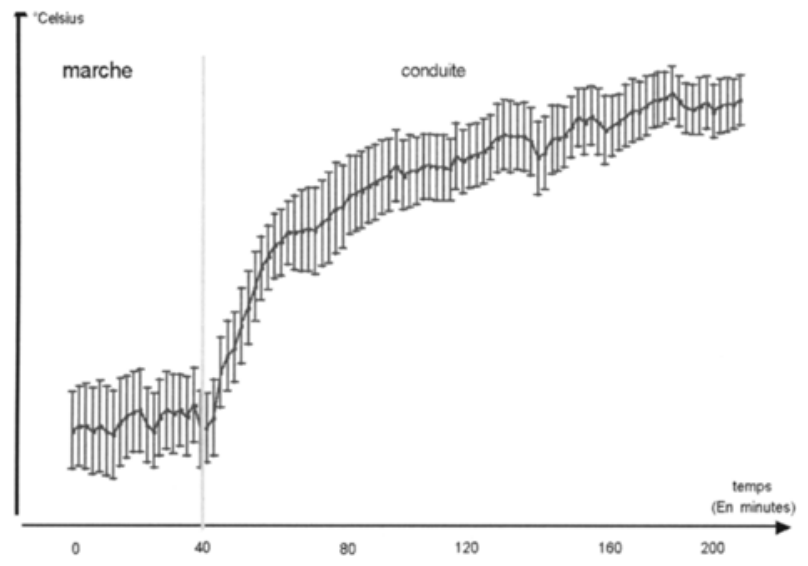

CONCLUSION : Le lien entre la conduite automobile et l'augmentation de la température scrotale, démontré dans notre étude, pourrait expliquer l'allongement du délai nécessaire pour concevoir et les anomalies des spermatozoïdes retrouvées chez des chauffeurs. Ainsi les heures de conduite apparaissent comme un possible facteur de risque pour la fertilité masculine. D'autres études sont nécessaires pour en évaluer les implications dans le domaine de l'infécondité masculine (aspect physiopathologique) ou dans celui des variations de la production des spermatozoïdes rapportées ces dernières années.

\section{Induction d'une hypothermie scrotale inten- se lors de la radiothérapie ou la chimiotherapie: étude de faisabilité}

L BUJAN1, J.M. BACHAUD1, M. DAUDIN1, M. SOULIÉ2, F. PONTONNIER1, R. MIEUSSET1

1 Groupe de Recherche sur la Fertilité Humaine, CSM-CECOS Service d'Uro-Andrologie CHU La Grave CHU Rangueil, 2 Département de Radiothérapie, Institut Claudius Regaud Toulouse.

INTRODUCTION: L'hypothermie corps entier a fait preuve d'une protection de la fonction testiculaire lors de l'irradiation chez la souris (Weiss 1959, Ashwood-Smith 1963) ainsi qu'une diminution de la fréquence des translocations chromosomiques induites. Plus récemment le groupe de B. Jégou a mis en évidence une protection très importante de la fertilité et une diminution des pertes embryonnaires (Velez De La Calle et al. 1994). Si plusieurs essais cliniques de protection de la spermatogenèse chez l'homme ont été réalisés, l'application de l'hypothermie scrotale comme moyen de protection n'a jamais été proposée.

Nous présentons une étude de faisabilité d'un refroidissement scrotal lors de la radiothérapie et de la chimiothérapie

METHODES : Quatre hommes ayant une radiothérapie à distance d'une orchidectomie pour tumeur séminomateuse sont volontaires pour participer à l'essai. L'hypothermie est induite grâce à un refroidisseur médical LP et un système scrotal dans lequel circule le fluide refroidi (31S, Lourdel, France). L'hypothermie commence au minimum 30 minutes avant et se poursuit au minimum 15 minutes après la séance de radiothérapie. Un patient avait une chimiothérapie, l'hypothermie débutant avant le début de la chimiothérapie et se poursuivant $30 \mathrm{~min}$. après l'arrêt de la perfusion. Une mesure de la température scrotale en regard du testicule restant a été effectuée lors d'une séance d'hypothermie.

RESULTATS : L'induction de l'hypothermie a provoqué une chute de la température scrotale chez tous les patients. Cette hypothermie n'a pas entraîné d'effets secondaires (tension artérielle, fréquence cardiaque) ni de douleurs chez les patients.

Données thermiques de deux patients (gauche : radiothérapie, droite : chimiothérapie)
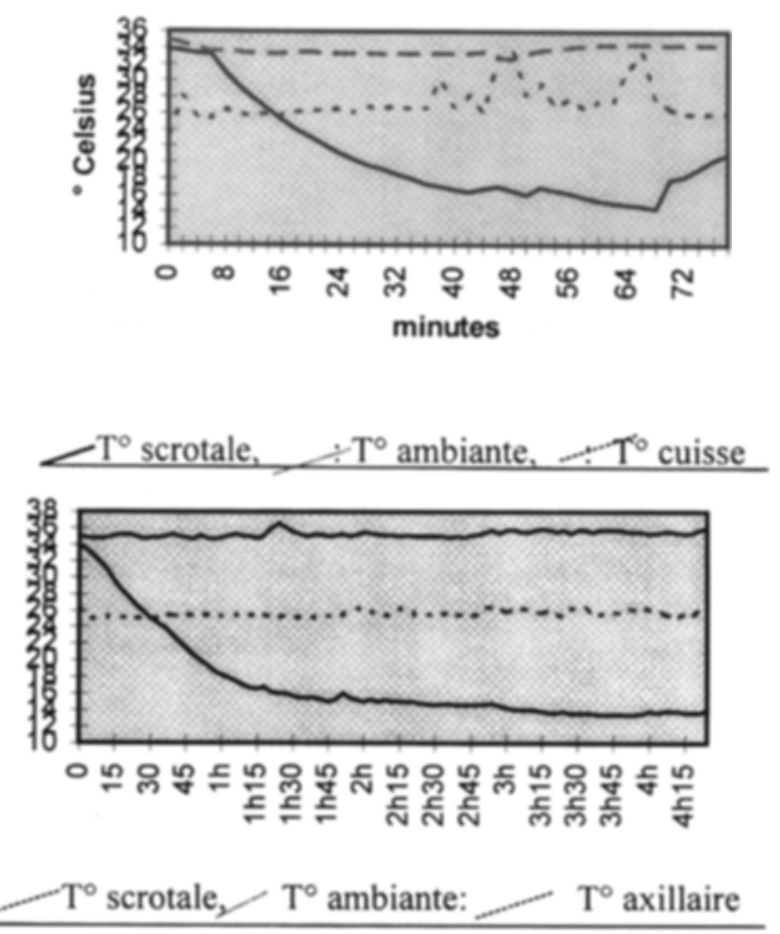
CONCLUSION : Il est possible, par la technique utilisée, d'amener la température scrotale entre 14 et $20^{\circ} \mathrm{C}$ avec une bonne tolérance clinique. Les travaux chez l'animal démontrent que l'hypothermie est un moyen efficace de protection de la spermatogenèse contre les effets délétères des radiations. Cependant les températures utilisées chez l'animal était nettement inférieures à celles obtenu dans notre étude. Il serait souhaitable d'évaluer l'efficacité de cette méthode en surveillant la spermatogenèse après radiothérapie chez un groupe protégé et un groupe témoin en rapport avec la dose gonadique reçue.

Projet soutenu par .- Délégation à La Recherche Clinique du C.H.L. de Toulouse 1994

\section{SPERMIOLOGIE}

\section{Concentrations du malondialdéhyde spermatique au sein d'une cohorte d'hommes fertiles}

\section{A. I.AUDAT, K. LECOURBE, A.M. PALLUEL \\ Centre Hospitalier; Laboratoire de Biochimie - Biologie de la Reproduction, B.P. 40 7, 28018} Chartres

Une augmentation de la peroxydation lipidique (PL) semble avoir de multiples effets délétères tant au niveau du spermogramme que du spermocytogramme. En effet, la concentration spermatique en malondialdéhyde (MDA), marqueur biochimique des phénomènes de $\mathrm{PL}$, est corrélée au pourcentage des formes vivantes, à l'importance de l'asthénospermie et/ou au pourcentage de spermatozoïdes présentant un profil morphologique de stress testiculaire (PST), [1, 2|. L'objectif de l'étude a été d'établir une première ébauche de valeurs normales de MDA spermatique au sein d'une population d'hommes fertiles.

Vingt patients fertiles (ayant déjà au moins 1 enfant) ont effectué un recueil de sperme au laboratoire (âge: $36 \pm 5,5$ ans, abstinence sexuelle: $3,9 \pm$ 1,4 jours). La numération des cellules rondes au sein de la totalité des échantillons s'est avérée être inférieure à 106/ml. Le MDA spermatique a été dosé immédiatement après éjaculation sur un échantillon de sperme par la technique à l'acide 2thiobarbiturique. Les résultats ont été exprimés par la moyenne \pm déviation standard et l'étude sta- tistique a été réalisée à l'aide du test non paramétrique de Spearman.

Les concentrations spermatiques en MDA, exprimées en nanomoles $/ 10^{8}$ spermatozoïdes, ont été de $0,392 \pm 0,0331$. Les pourcentages de PST ont été de $24 \pm 1$ 1. Le MDA spermatique s'est trouvé positivement corrélé avec le résultat du PST (rho : +0,551,p $=0,0163$ ).

La détermination du MDA spermatique est simple, rapide, peu coûteuse et ne nécessite pas de matériel sophistiqué. Si le dosage du MDA au niveau du liquide séminal semble ne présenter aucun intérêt [3], la quantification de ce composé au niveau même du spermatozoïde apporte de précieux renseignements sur l'origine probable d'une asthénospermie supposée d'origine métabolique et/ou la baisse inexpliquée de la vitalité. Le suivi de ce marqueur spermatique pourrait être également intéressant avant et après la mise en place d'un traitement visant à minimiser les phénomènes de PL et/ou améliorer la qualité des spermatozoïdes d'un patient (traitement anti-oxydant, antibiothérapie, cure de varicocèle, etc ... ). Enfin, compte tenu d'une part des variabilités intra- et inter-observateurs lors de l'évaluation du pourcentage de PST, et d'autre part de la corrélation existant entre le PST et le MDA, la détermination de la concentration spermatique en MDA apparaît comme un marqueur plus fiable que l'appréciation en microscopie du PST. Il est néanmoins nécessaire de poursuivre cette étude sur un grand nombre de patients afin de pouvoir dégager des "valeurs normales " totalement fiables en MDA spermatique chez l'homme fertile.

1 Laudat A, Palluel A. M. Malondialdéhyde spermatique et anomalies cytologiques constitutives du profil morphologique de stress testiculaire. Andrologie 1999, 9.- 116.

2 Laudat A, Palluel A.M. Profil de stress testiculaire et peroxydalion lipidique. 3èmes Journées de la Fédération Française d'Etude de la Reproduction, 2325 Septembre 1998, Paris.

3 Laudat A, Lecourbe K, Palluel A. M. Peroxydation lipidique, profil morphologique de stress testiculaire et maturité nucléaire des spermatozoïdes. Ann Biol Clin 1999, 5 7.- 51-56.

\section{Evaluation des différentes sous-populations de cellules germinales dans le sperme humain par cytométrie en flux}

L. CORCIA 1, Y. LEVERGNE 2 D. KERBOEUF2, C.BARTHELEMY 3, S.HAMAMAH 4 


\section{Laboratoire de biologie polyvalente $\mathrm{CH}$ Dreux 2 INRA Nouzilly 3 CECOS Tours, Hôpital Bretonneau 4 Centre de Fécondation in vitro, Hôpital A. Béclère, 92141 Clamart.}

Introduction: les premières naissances rapportées après microinjection de spermatides correspondent le plus souvent à des situations où le blocage de la spermiogenèse n'était pas complet, mais où l'absence de spermatozoïde constatée le jour de la microinjection était un élément nouveau, inattendu, alors que des spermatozoïdes avaient été trouvés dans les éjaculats précédents. Un point crucial avant d'évaluer les résultats de cette nouvelle méthode thérapeutique est de reconnaître avec fiabilité la spermatide ronde à injecter. Pour évaluer cette nouvelle approche thérapeutique, plusieurs questions se posent: (1) la reconnaissance subjective de spermatides dans l'éjaculat est elle fiable en pratique dans un centre d'AMP? (2) existait-il des moyens objectifs pour la reconnaissance des spermatides dans l'éjaculat?

But : L'objet de notre travail a été de valider la technique de cytométrie en flux (CMF) comme outil diagnostique permettant l'évaluation des différentes sous-populations cellulaires de la lignée germinale du sperme humain.

Matériels et méthode: l'étude par CMF (analyseur-trieur de cellules FAC-Star), a porté sur 58 éjaculats répartis en 3 groupes : spermes normaux (contrôle), spermes OAT modérés et spermes OAT sévères ou azoospermie. Les résultats sont exprimés sous formes d'histogrammes biparamétriques portant en abscisse l'intensité de la fluorescence émise et en ordonnée un signal de diffusion de la lumière (SSC: Side Scatter qui correspond à la lumière diffusée à angle droit). L'analyse de la fluorescence de l'iodure de propidium, a permis l'individualisation, sur les histogrammes biparamétriques, de 4 régions correspondant à 4 sous-populations cellulaires de la lignée germinale réparties dans des canaux de fluorescence distincts: Une région de cellules haploïdes correspondant aux spermatozoïdes (RI), une région de cellules sub-haploïdes (spermatides (R2), une région de cellules diploïdes (spermatogonies en phase GI du cycle cellulaire, les spermatocytes de premier ordre au stade pré-leptotène de la prophase de la lère division méiotique, les spermatocytes de second ordre et les cellules somatiques) (R3), une région des cellules tétraploïdes (spermatogonies en phase G2 du cycle cellulaire, spermatocytes de premier ordre au stade leptotène et post-leptotène de la prophase de la première division méiotique et certaines cellules somatiques en phase G2) (R4).

Résultats: Nous avons observé une quasi-absence des sous-populations germinales diploïdes et tétraploïdes pour les spermes normaux par rapport aux spermes déficients qu'ils soient oligospermiques modérés ou sévères.

Discussion et conclusion: notre étude a permis d'évaluer objectivement le \% des différentes souspopulations cellulaires haploïdes, sub-haploïdes, diploïdes et tétraploïdes présentes dans le sperme des patients infertiles. Nous avons également observé une différence significative du \% des cellules diploïdes et tétraploïdes entre les trois groupes étudiés. L'analyse par CMF du contenu en ADN des différentes sous-populations cellulaires au sein d'un éjaculat pourrait ouvrir la voie à de nouvelles stratégies diagnostiques et pronostiques de l'infertilité masculine : si les résultats obtenus à partir d'un éjaculat sont corrélés à ceux obtenus à partir d'un échantillon de tissu testiculaire pour un même patient, il sera alors possible à la fois de caractériser le trouble de la spermatogenèse à partir d'un éjaculat et d'évaluer la probabilité de retrouver des spermatozoïdes si une biopsie testiculaire doit être réalisée.

\section{$\%$ de cellules haploïdes}

sperme normal

OAT modéré

OAT sévère ou

$88,6 \pm 2,9^{*}$

$66,1 \pm 3,1$

$34,2 \pm 5,9$

azoospermie
$\%$ de cellules subhaploïdes

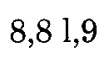

$21,11,7$

$19,14,4$

\section{$\%$ de cellules diploïdes}

$$
\begin{aligned}
& 1,1 \pm 0,4^{* *} \\
& 7,9 \pm 0,8 \\
& 18,2 \pm 7,0
\end{aligned}
$$

$\%$ de cellules tétraploïdes

$$
\begin{aligned}
& 0,3 \pm 0,02^{* *} \\
& 4,9 \pm 1,2 \\
& 28,6 \pm 9,7
\end{aligned}
$$

Les valeurs sont exprimées en moyenne \pm SEM. $* \mathrm{p}=0.002,{ }^{* *} \mathrm{p}=0.03$

Par ailleurs, il existe une différence significative du \% de cellules haploïdes en fonction de la concentration spermatique. 


\section{Apport du spermogramme dans le dépistage du varicocèle chez l'homme infertile.}

L. AMMAR-KESKES1, A. SELLAMI-BEN HAMIDA1, D. LTAIEF3, N. BOUAYED-ABDELMOULA1, N. CHAKROUN-FKI1, F. BOUZID3, N. MHIRI2 S. REKIK1, T. REBAÏ1

1 Laboratoire d'Histologie, Faculté de Médecine, Avenue Majida Boulila, CP: 3028, Sfax, 2 Service d'Urologie, CHU Habib Bourguiba, Sfax, .

3 Service de Gynécologie-Obstétrique, CHU Hédi Chaker, Sfax, Tunisie.

Introduction : De nombreuses études ont démontré l'implication du varicocèle dans l'altération de la spermatogenèse et de la qualité du sperme [1]. Les anomalies spermiologiques habituellement associées au varicocèle sont l'oligo-asthénospermie et la tératospermie. Celle-ci est caractérisée essentiellement par un taux élevé de têtes allongées, amorphes ou immatures, associée à des degrés variables à des anomalies de la pièce intermédiaire.

Le but de notre travail était de montrer l'intérêt de l'étude morphologique des spermatozoïdes dans le dépistage du varicocèle chez l'homme infertile.

Matériels et Méthodes : Cette étude rétrospective a porté sur 111 patients répartis en deux groupes: un groupe GI, composé de 61 patients ayant bénéficié d'un spermogramme dans le cadre d'un bilan d'infertilité et chez lesquels un profil évocateur de varicocèle a été identifié au spermocytogramme. Ce profil était défini par la présence d'au moins $10 \%$ de spermatozoïdes à tête allongée. Une échographie doppler des veines spermatiques a été pratiquée chez tous les patients de ce groupe, en vue d'une confirmation du diagnostic. Le deuxième groupe (G2) était composé de 50 patients connus porteurs de varicocèle, diagnostiqué par échographie doppler et chez lesquels un spermogramme a été pratiqué afin d'évaluer le retentissement sur la qualité du sperme. Les spermogrammes étaient effectués selon la méthode standardisée de l'OMS [2]. L'analyse morphologique des spermatozoïdes était basée sur la classification de David |3|.

Résultats : Le diagnostic de varicocèle a été confirmé par l'échographie doppler dans 92\% (56/61) des cas de Gl. Les valeurs moyennes des paramètres du spermogramme ainsi que les taux moyens des principales anomalies morphologiques dans GI et G2, ne montrent pas de différences significatives. La fréquence de l'asthénospermie était respectivement de $76,6 \%$ et de $76,3 \%$ dans GI et G2. L'asthénospermie sévère (mobilité $<30 \%$ ) était cependant, plus fréquente dans G2 $(28,9 \%$ contre $18,3 \%$ dans GI). Bien que tous les patients de GI avaient une numération $>1$ million $/ \mathrm{ml}, 40,6 \%$ d'entre eux étaient oligospermiques. La fréquence de l'oligospermie dans G2 était de 52,1\% (azoospermie exclue). L'oligospermie était extrême dans $22,7 \%$ des cas de ce groupe. La fréquence de l'azoospermie était de $12 \%$. La morphologie était perturbée dans $56,6 \%$ et $64,1 \%$ des cas de GI et 02 , respectivement. La tératospermie sévère (morphologie normale $<10 \%$ ) était observée chez $10 \%$ des patients de GI et chez $15.3 \%$ de ceux de G2. Le profil de varicocèle était retrouvé dans seulement $51,2 \%$ des cas de G2.

Discussion - Notre étude montre que l'analyse morphologique des spermatozoïdes est d'un grand apport pour le dépistage du varicocèle, puisque le diagnostic suspecté sur les données de l'analyse morphologique a été confirmé dans la quasi totalité des cas. Cette étude confirme également l'effet néfaste $\mathrm{du}$ varicocèle sur la qualité du sperme, puisque les fréquences respectives de l'oligospermie et de la tératospermie étaient plus élevées que celles rapportées précédemment chez l'homme infertile en général [4], Le dépistage par le spermogramme permet de découvrir précocement le varicocèle et d'empêcher l'aggravation des anomalies spermatiques. En effet, l'asthénospermie et la tératospermie sévères ainsi que l'oligospermie extrême étaient plus fréquentes lorsque le diagnostic de varicocèle était déjà porté et elles semblent indiquer un stade évolutif de l'anomalie.

Il ressort aussi de cette étude que l'allongement de la tête spermatique ne constitue pas une anomalie constante du varicocèle, puisqu'elle n'était présente que dans environ la moitié des cas de G2 - mais son existence à des taux élevés est très évocatrice du diagnostic.

1 BISERTE. J, LEMAITRE. L, RIGOT. J.M: Varicocèle. Editions techniques. EMC, Néphrologie Urologie 18648 10,1992,10p.

2 AUGER J., JOLANNET P. : Valeurs de référence des caractéristiques du sperme. In: Auger J., Jouannet P., Ed INSERM. Manuel de laboratoire de l'OMS. Analyse du sperme humain et de linteraction des spermatozoïdes avec le mucus cervical, Paris, 1993: 45-46.

3 DAVID G., BISSON JP., CZYGLIK F. et al: Anomalies morphologiques du spermatozoïde humain. 1) Proposition pour un système de classification. J. Gyn. Obst et. Biol. Reprod., 1975, 4 suppl 1 : 17-36.

4 AMMAR-KESKES, L, KALLEL. N, BOUZID, F, REKIK. S, REBAI. T: Caractéristiques cytomorphologiques du sperme chez les hommes consultant pour infertilité du couple dans la région de Sfax, Andrologie, Vol 8, N'3, 1998. 


\section{Délai nécessaire pour concevoir et caracté- ristiques spermatiques: une étude transver- sale auprès de 928 couples européens fertiles.}

R. SLAMA, B. DUCOT, F. EUSTACHE, J. AUGER, N. JORGENSEN, J. TOPPARI, S. IRVINE, T. KOLD JENSEN, A. SPIRA.

INSERM, U292, Hôpital de Bicêtre, 82 av. du Gal Leclerc, 94276 Le Kremlin Bicetre cedex

Etat de la question : Le délai nécessaire pour concevoir (DNC), nombre de cycles menstruels sans contraception nécessaires à un couple pour obtenir une grossesse, constitue un indicateur synthétique de la fertilité utilisé en épidémiologie -, cependant, la sensibilité du DNC aux variations des caractéristiques spermatiques est mal connue en population générale.

Matériel et méthodes : L'objectif de notre travail était l'étude des relations entre caractéristiques spermatiques et DNC, dans un échantillon de 928 couples européens volontaires dont la femme était enceinte depuis plus de 3 mois lorsque l'homme a fait un prélèvement de sperme. Toutes les grossesses avaient été obtenues sans assistance médicale. L'analyse centralisée (Paris) de la morphologie spermatique a été réalisée selon les critères de David modifiés, et l'index d'anomalies multiples (IAM, nombre moyen d'anomalies morphologiques par spermatozoïde anormal) a été calculé. En décomposant le DNC en mois et en analysant l'issue binaire de chaque mois par régression binomiale avec la fonction de lien complémentaire log-log, nous avons ajusté les risques relatifs instantanés de grossesse sur les caractéristiques de la partenaire, et recherché des seuils pour l'effet des variables spermatiques sur la probabilité de conception.

Résultats : Les proportions de couples n'ayant pas conçu au bout de 6 mois de tentatives étaient respectivement de $31 \%$ et $17 \%$, selon que la proportion de spermatozoïdes normaux était inférieure ou supérieure à $25 \%(\mathrm{p}=0.008)$. Le risque relatif de survenue d'une grossesse en 6 mois de tentatives était de 0,84 (IC 95\%: $[0,71,0,99]$ ) chez les sujets ayant moins de $25 \%$ de spermatozoïdes normaux, de 0,94 (IC $95 \%$ : $[0,89,1,01]$ ) si l'IAM était supérieur à 1,6, et de 0,86 (IC 95\%: [0,74 -, 1,00]) pour une concentration spermatique inférieure à $20 \times 106 / \mathrm{ml}$. Les analyses ajustées sur les caractéristiques de la partenaire et le délai d'abstinence ont confirmé ces tendances. Des augmentations de la proportion de spermatozoïdes normaux ou de la concentration spermatique n'étaient associées à une probabilité de fécondation diminuée qu'en dessous de $26 \%$ de spermatozoïdes normaux, et 5 $9 \mathrm{XI} 06 / \mathrm{Ml}$, respectivement. Une augmentation de l'IAM était associée à une augmentation du DNC sur toute l'étendue des valeurs de l'IAM.

Conclusions : Cette étude indique pour la première fois un seuil à $26 \%$ pour l'effet de la proportion de spermatozoïdes normaux sur la probabilité de conception. Complémentaire et partiellement indépendant de cette variable, l'IAM se révèle être un indicateur sensible de la fertilité. La moindre fertilité des couples féconds ayant une concentration spermatique inférieure à $20 \times 106 / \mathrm{ml}$ est confirmée, mais la concentration spermatique pourrait influencer le DNC pour des valeurs aussi hautes que $60 \times 106 / \mathrm{ml}$.

\section{AMP}

\section{Morphologie des spermatozoïdes migrés et résultats des inséminations intrautérines (IIU) avec sperme du conjoint}

\section{LAZREK1, B. MARTIN-PONT1, A. TEM- STET1, I. CEDRIN-DURNERIN2, J.N. HUGUES2, J.Ph WOLF1}

1 Service d'Histologie Embryologie Cytogénétique Biologie de la Reproduction2 Service de Médecine de la Reproduction, Hôpital Jean Verdier, Bondy

Mots clés : spermatozoïdes - stérilité masculine IIU

INTRODUCTION L'IIU avec sperme de conjoint est une méthode largement utilisée en Assistance Médicale à la Procréation (AMP). L'influence de la morphologie des spermatozoïdes sur son résultat n'a cependant été étudiée qu'à partir du sperme de l'éjaculat non sélectionné avec des résultats contradictoires. Cette étude prospective se propose d'évaluer les résultats des IIU en fonction de la morphologie du sperme sélectionné effectivement inséminé, sachant qu'elle diffère substantiellement de celle du sperme frais (Hall et al.).

Les leucocytes ont un effet délétère sur les spermatozoïdes par le biais de processus oxydatifs (Aitken Biol Reprod 1998, 59: 1037-46).

MATERIEL ET METHODE118 cycles consécutifs d'IIU pour 80 couples ont été analysés de Septembre à Décembre 1998. Les pathologies spermatiques représentaient $44 \%$ des indications, les causes féminines (cervicale, tubaire relative) $40 \%$ 
et les infertilités inexpliquées $16 \%$. Un frottis a été systématiquement réalisé à partir du sperme préparé (migration ascendante $28 \%$ des cas et gradient de Puresperm 72\%). Après coloration au Papanicolaou, 100 spermatozoïdes ont été lus par lame et par un même observateur en utilisant la grille de classification de David modifiée (David, 1975, Jouannet, 1988).

RESULTATS Le taux de grossesses cliniques (un sac à l'échographie) était de 16,1\% par cycle et de $23,7 \%$ par couple. L'analyse des issues d'insémination par cycle a montré un taux supérieur mais non significatif des formes typiques dans le groupe des patients ayant obtenu une grossesse $(35,6 \%$ versus $30,7 \%$ ). Par contre, les pourcentages des polynucléaires, des fragments cellulaires et des flagelles isolés étaient significativement plus élevés dans le groupe sans grossesse.

$\begin{array}{llll}\begin{array}{l}\text { Fréquence } \\ \begin{array}{l}\text { (en pourcentage } \\ \text { des spermatozoïdes) }\end{array}\end{array} & \begin{array}{l}\text { Groupe } \\ \text { grossesse }\end{array} & \begin{array}{c}\text { Groupe } \\ \text { sans } \\ \text { grossesse }\end{array} & \mathrm{p} \\ \text { Formes typiques } & 35,6 & 30,7 & 0,03 \\ \text { Polynucléaires } & 0,01 & 0,09 \pm 0,043 & 0,03 \\ \text { fragments cellulaires } & 0,05 \pm 0,23 & 0,60 \pm 2,23 & 0,04 \\ \text { flagelles isolés } & 1,58 \pm 1,64 & 2,77 \pm 4,37 & 0,02\end{array}$

L'analyse par couple a montré des résultats similaires.

CONCLUSION Les signes d'altérations cellulaires associés à une augmentation des leucocytes séminaux suggèrent la présence d'un syndrome inflammatoire délétère associé avec une chute du taux de grossesse.

Ces résultats doivent être confirmés par une étude plus large influence de l'etiologie de l'azoospermie dans les résultats biologiques et cliniques en ICSI ?

Influence de l'étiologie de l'azoospermie dans les résultats biologiques et cliniques en ICSI?

\section{F. GUERIF, C. BARTHELEMY, J. POINDRON, R. BIDAULT, J. LANSAC, D. ROYERE \\ Laboratoire de Biologie de la Reproduction. Département de Gyn. Obst CHU Bretonneau 2, bis boulevard Tonnellé 37044 Tours Cedex}

INTRODUCTION : Le diagnostic d'azoospermie recouvre en fait des étiologies très diverses (causes secrétoires ou excrétoires congénitales ou acquises).
L'injection intracytoplasmique de spermatozoïdes (ICSI) prélevés au niveau des voies génitales a permis de repousser les limites de la stérilité masculine. Cependant, il est encore indispensable de colliger un nombre important de données biologiques et cliniques sur les ICSI réalisées avec sperme épididymaire ou testiculaire afin de confirmer définitivement les résultats initiaux encourageants et rassurants.

MATERIEL ET METHODES : Une étude rétrospective portant sur la période mai 1995 - juillet 1999 a permis d'analyser 98 cycles d'ICSI (MESA ou TESA) dans le cadre d'azoospermies. En fonction de l'étiologie, une classification en 3 groupes a été pratiquée (GI : atrésie des canaux déférents (ACD), $\mathrm{n}=47$ / G2 : étiologie excrétoire acquise, $\mathrm{n}=40$ / G3 : étiologie sécrétoire, $n=11$ ). Aucune différence significative entre les groupes n'a été retrouvée concernant l'âge des femmes, les pathologies féminines associées (indication tubaire, dysovulation, endométriose) et la durée d'infécondité. Par contre, l'âge des hommes du groupe $2(37,4 \pm 5,8$ ans) est significativement plus élevé par rapport à celui des groupes 1 et $3(33,1 \pm 4,4$ ans et $33,4 \pm 2,9$ ans respectivement ; $p<0,05)$. Tous les ovocytes ont été microinjectés avec des spermatozoïdes mobiles. L'analyse statistique des résultats a consisté en l'analyse de variance (Statview 4. 1).

RESULTATS : Au sein des 3 groupes, les nombres moyens d'ovocytes fécondables (G $1: 6,9 \pm 3,7$ / G2 : $6,6 \pm 3,3$ / G3 : 5,6 \pm 11 ) ne diffèrent pas statistiquement. Le taux de fécondation est similaire quelle que soit l'étiologie (GI : $49 \pm 30 \%$ / G2 : $45 \pm 28 \%$ / G3 : $32 \pm 21 \%$ ) ainsi que le taux de clivage (GI : $55 \pm 30 \%$

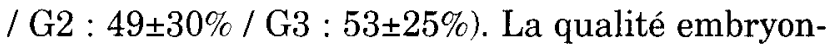
naire ne diffère pas selon les groupes comme en témoigne la similitude des résultats concernant aussi bien le nombre moyen d'embryons de grade 1 obtenus que le nombre moyen d'embryons de grade 3 obtenus ou le pourcentage de cycles permettant la congélation à J2 d'embryons surnuméraires sur des critères très stricts (4 cellules régulières sans fragments). Au final pourtant, si le taux de grossesse clinique par ponction varie peu quelle que soit l'étiologie de l'azoospermie (GI : 23,4\%, G2 : 17,5\%, G3 : $18,2 \%$ ) et cela pour un nombre moyen d'embryons transférés ne différant pas significativement entre les groupes (GI : $2,1 \pm 0,6, \mathrm{G} 2: 2,2 \pm 0,6$, G3 : $2,4 \pm 0,7$ ), il est à remarquer toutefois un taux d'implantation plus faible dans le groupe $2(9,0 \%)$ par rapport aux groupes 1 et $3(16,5$ et $12,5 \%$ respectivement).

CONCLUSION : Dans notre étude, après ICSI, l'étiologie de l'azoospermie ne semble pas influer le taux de fécondation, le développement et la qualité 
embryonnaire. Toutefois, les meilleurs résultats sont obtenus dans les azoospermies excrétoires congénitales. Les données de la littérature sont controversées à ce sujet, ainsi Thiounn et coll., 1997 et Adjiman et coll., 1996 observent des résultats similaires aux nôtres à la différence de Palermo et coll., 1999. Un nombre plus important de cas semble cependant indispensable pour confirmer les données de cette série.

\section{Fécondation assistée (ICSI) avec sperme tes- ticulaire frais ou décongélé dans des dysgy- nesies gonadiques pures de Klinefelter.}

\author{
Y. SOFFER1, S. FRIEDLER2, A. RAZIEL2, \\ S. KAUFMAN1, A. UMANSKI1, R. RON-EL2, \\ D. STRASSBURGER2
}

1 Centre d'infertilité masculine 2 Unité de FIV, Faculté de médecine Sackler, Université de Tel Aviv, Centre médical Assqf' Harofé, Zérifin, Israël.

INTRODUCTION : 7 cas de Klinefelter avec hypogonadisme hypergonadotrope, gynécomastie, petits testicules, azoospermie et caryotype $47 \mathrm{XXY}$ unique ont été traités par ICSI.

\section{LE BUT DE CE TRAVAIL}

Evaluer les résultats de l'ICSI avec des spermatozoïdes testiculaire frais [1] ou cryopréservés dans des cas de Klinefelter et d'en rapporter les premières naissances avec des spermatozoïdes décongelés.

\section{MATERIEL ET METHODES}

Après examen complet, bilan hormonal et confirmation du caryotype 47,XXY unique sur plus de 30 lymphocytes, une recherche minutieuse de spermatozoïdes a été pratiquée dans plusieurs éjaculats, et

$\begin{array}{lll}\text { Procédure Ovocytes } & \text { fécondés } & \text { clivés } \\ \begin{array}{l}\text { TESE-ICSI } 39 \\ \begin{array}{l}3 \text { cycles avec sperme } \\ \text { testiculaire frais }\end{array}\end{array} & 30 & 29 \% \\ \begin{array}{l}\text { Décongélation } 34 \\ 4 \text { cycles avec sperme } \\ \text { testiculaire décongelé }\end{array} & (77 \%) & (97 \%) \\ \end{array}$

in extremis le jour de la ponction ovocytaire. Si des spermatozoïdes mobiles ont été découverts, ils ont été utilisés en ICSI. Si non, un prélèvement testiculaire a été fait (TESE). Après ICSI, les spermatozoïdes surnuméraires ont été congelés [2] pour être utilisés plus tard. 2 à 3 embryons par cycle ont été transférés. Seules les grossesses cliniques avec sac gestatoire ont été prises en considération.

\section{RESULTATS}

Les sujets étaient âgés de $27,4 \pm 3,6$ ans. Les taux de FSH était de $41,9 \pm 11,9 \mathrm{UI} / \mathrm{L}$ et de testostérone $6,4 \pm 4,1 \mathrm{nmol} / \mathrm{mL}$. Les testicules étaient très petits (2 à $4 \mathrm{ml}$ ). Des spermatozoïdes immobiles ont été trouvés dans l'éjaculat dans 2 cas sur 7. Dix ovocytes ont été injectés avec du sperme immobile sans donner de fécondation. Dès lors, le sperme immobile n'a plus été utilisé. Les résultats de l'ICSI avec sperme testiculaire frais et décongelé de Klinefelter pur est présenté ci-dessous

Aucune différence significative $(p>0,05)$ n'a été trouvée dans les taux de fécondation, de clivage et d'implantation avec le sperme frais ou décongelé.

CONCLUSION : Comme dans toutes les azoospermies sécrétoires, l'ICSI est souvent possible dans les cas de Klinefelter pur. Des spermatozoïdes mobiles doivent être recherchés dans l'éjaculat. Si l'on n'en trouve pas, on a de bonnes chances d'en prélever dans les testicules, de préférence sous biopsie. Des grossesses normales ont été obtenues. Nous rapportons les deux premières grossesses, dont une gémellaire, avec sperme testiculaire décongelé de dysgénésies gonadiques pures de Klinefelter. Les implications génétiques des fécondations assistées pratiquées dans ces cas doivent être expliquées aux couples concernés ainsi que la nécessité de pratiquer un diagnostic génétique prophylactique pré-implantatoire ou prénatal.

\section{RÉFÉRENCES :}

1 Ron-El et al. Hum. Reprod. 1998, 14, 35 8-70;

2 Friedler et al. Fertil. Steril.,1997, 68:892-97

$\begin{array}{lll}\text { transférés } & \text { Implantés } & \text { Grossesses } \\ 9 & \begin{array}{l}4 \\ (44,4 \%)\end{array} & \begin{array}{l}1 \text { nouveau -né } \\ 1 \text { triplés en cours }\end{array} \\ 14 & 3 & \begin{array}{l}1 \text { avortement } \\ \text { précoce } \\ 1 \text { gémellaire } \\ \text { en cours }\end{array} \\ & (21.4 \%) & \end{array}$




\section{Prise en charge thérapeutique d'un syndrome de Kartagener par ICSI : Etude d'un cas}

F. ARNAL, T. ATIABORY, D. LAUTON, K. WENZEL, C. HUMEAU

CHU de Montpellier

Objectif: évaluer la possibilité de prise en charge thérapeutique d'un syndrome d'immobilité ciliaire, cause rare d'infertilité masculine, par Injection Intra Cytoplasmique de Spermatozoïde (ICSI).

Patient : cas d'un homme, atteint d'un syndrome de Kartagener (situs inversus, sinusite chronique, infertilité masculine dont le spermogramme a révélé l'absence complète de spermatozoïde mobile, malgré une morphologie et une viabilité normale $(80 \%$ de viabilité).

Etude en microscopie électronique à transmission : confirmation du syndrome de Kartagener. Structure axonémale normale avec, absence totale des bras de dynéine.

Stimulations : 3 cycles de stimulation ont été réalisés chez la conjointe et les ovocytes prélevés ont été traités par ICSI.

Résultats : $26 \%$ des ovocytes ont été fécondés Les embryons obtenus ont été transférés chaque cycle. Le dernier transfert a donné lieu à une grossesse biologique.

Conclusion : L'ICSI semble représenter une solution thérapeutique prometteuse de la prise en charge du syndrome de Kartagener. Néanmoins le risque génétique ne peut être négligé. Un conseil génétique et une information rigoureuse doivent être transmise au couple.

Autoconservation pour cancer testiculaire analyse rétrospective sur 20 ans (1979-1998)

\section{BARTHELEMY, F. GUERIF, J. LANSAC, D. ROYERE}

CECOS - Biologie de la Reproduction, Département de Gynécologie- Obstérique CHUBretonneau 37044 Tours

Population étudiée : Pendant cette période 328 patients ont été adressés pour une autoconserva- tion pour cancer testiculaire (tumeurs germinales et non germinales). La demande a été multipliée par 3 dans les 10 dernières années.

Pour 287 d'entre eux (87\%) un diagnostic précis était connu: $40 \%$ de séminomes $60 \%$ de tumeurs non séminomateuses (dont $\mathbf{6 5 \%}$ de tumeurs mixtes). Le stade était précisé dans 1 cas sur $2.8 \%$ avaient des antécédents de cryptorchidie ou d'ectopie , $1,5 \%$ de cancer testiculaire familial, $4,7 \%$ des antécédents testiculaires autres.

L'âge moyen des patients atteints de séminomes était significativement plus élevé que celui des autres types $(30,9 \pm 5,2$ vs $27,3 \pm 5,1$ ( $p<0,001)$.

De même les patients atteints de séminomes vivaient plus souvent en couples $(73 \%$ vs $\mathbf{4 7 \%}$ ) et avaient en moyenne plus d'enfants ( $46 \%$ vs $29 \%$ ) $(\mathrm{p}<0,001)$

$\mathbf{5 , 9 \%}$ des patients n'ont bénéficié d'aucun traitement, $33 \%$ ont eu une radiothérapie, $\mathbf{5 7 \%}$ une chimiothérapie dont les $3 / 4$ à base de cisplatine (protocole EP ou BEP).

Il y a une corrélation étroite entre le traitement et le type de la tumeur $\mathrm{p}<0,001$ ), radiothérapie pour le séminome (dose souvent< $30 \mathrm{~Gy}$ ), chimiothérapie celui des tumeurs non séminomateuses ou métastasées. Le nombre de cures moyen était supérieur à 3 cycles. Dans les tumeurs mixtes, un curage ganglionnaire a été fait ensuite dans 1 cas sur 2 .

Autoconservation : Pour 3 patients sur 4 l'autoconservation était demandée après l'orchidectomie. $42 \%$ avaient une numération spermatique $>20$ Millions par ml mais $36 \%$ seulement une mobilité $>30 \%$ si bien que le test de décongélation était souvent peu favorable ( $81 \%$ )

La congélation s'est avérée impossible dans $\mathbf{2 0 \%}$ des cas soit par échec de recueil $(2 \%)$ ou à cause de la qualité spermatique ( $9 \%$ azoospermies, $9 \%$ d'oligozoospermies très sévères). En moyenne plus de 40 paillettes ont été conservées par patient avec un nombre de recueils moyen de 2,7 .

Devenir : 25\% des patients non perdus de vue ont contrôlé leur spermogramme, les caractéristiques du sperme à distance dépendent à la fois de leurs caractéristiques de départ et du nombre de cures de chimiothérapie $(\mathrm{p}<0,05)$.

41 patients, dont 16 étaient déjà pères, ont eu des enfants avec un délai moyen de 3 ans après le traitement (chimio ou radiothérapie) : 33 ont procréé spontanément . $\mathbf{2 0}$ couples ont utilisé des paillettes en PMA ( 10 IAC, 5 FIV, 7 ICSI ), 11 enfants sont nés ( 8 par IAC, 1 par FIV, 2 par ICSI), parmi eux 2 couples ont procréé ensuite spontanément. Il y a eu 
5 échecs et 6 résultats sont non connus (transferts)

$\mathbf{5 8 , 5 \%}$ conservent encore leurs paillettes, $\mathbf{1 2} \%$ seulement sont perdus de vue, $\mathbf{2 9 , 5 \%}$ ont décidé l'arrêt de la conservation et 7 patients sont décédés.

\section{Quel est l'apport de l'I.C.S.I après paucifécondation en F.I.V classique ?}

\author{
0. PAULMYER-LACROIX, J. BALZANO, M. \\ MOLLAR-FABBRICELLI, J. SAIAS-MAGNAN, \\ G. PORCU, F. CARLES, A. NOIZET J.M. GRILLO \\ Laboratoire de Biologie de la Reproduction, CPMA, \\ CHU La Conception, 147 Bd Baille, 13005 \\ Marseille
}

Nous avons étudié rétrospectivement les résultats de l'I.C.S.I. proposée aux couples après paucifécondation en F.I.V. classique.

Matériel et méthodes Notre étude concerne 24 couples pour lesquels une Fécondation In Vitro (FIV) classique avait été proposée en raison d'une infertilité d'origine masculine $(n=12)$, tubaire $(n=2)$, mixte (n--9) ou idiopathique $(n=l)$. Devant la paucifécondation obtenue au cours de ces tentatives ( $\mathrm{n}=38$ ), nous avons réalisé les F.I.V. en utilisant la microinjection (I.C.S.I., $\mathrm{n}=36$ ).

Nous avons étudié plus particulièrement le taux de fécondation (\% zygotes à $2 \mathrm{PN} /$ nombre d'ovocytes fécondables) et le taux de grossesse dans ces 2 groupes (F.I.V classique et I.C.S.I.). L'étude statistique a été réalisée par Anova ou par le test du Ch12.

Résultats : Le nombre moyen d'ovocytes recueillis et fécondables, ainsi que les paramètres moyens du spermogramme le jour de la tentative sont comparables dans ces 2 groupes.

Le taux de fécondation est significativement plus important dans le groupe I.C.S.I. $(47,2 \% \pm$ 4,3 versus $19,8 \% \pm 3,2$ en $171 \mathrm{~V}$ classique, p $<0,05)$. Le nombre moyen d'embryons normaux, i.e issus de zygotes à $2 \mathrm{PN}$, est de 3,3 \pm 0,51 en I.C.S.I. et de $1,6 \pm 0,25$ en F.I.V. classique $(p<0,05)$.

Le nombre moyen d'embryons transférés est équivalent dans les 2 groupes (2,05 en I.C.S.I., 1,6 en F.I.V. classique, $\mathrm{p}>0,05$ ).
Le taux de grossesse par ponction est comparable dans les 2 groupes $(11,1 \%(4 / 36)$ en I.C.S.I. vs $7,8 \%$ (3/38) en F.I.V. classique, pO,05).

Conclusion : Notre étude met en évidence une amélioration nette du taux de fécondation et du nombre d'embryons obtenus après I.C.S.I., mais sans réel bénéfice en ce qui concerne la survenue de grossesse.

Il est à noter que le taux de fécondation en I.C.S.I. dans notre étude est plus faible que celui généralement observé dans les indications masculines avec altérations sévères du spermogramme (de l'ordre de $60 \%$ ).

La paucifécondation en F.I.V. classique pourrait donc être à la fois la conséquence d'anomalies spermatiques et d'anomalies ovocytaires.

Représentation des risques liés aux techniques d'assistance médicale à la procréation et comportement des médecins face aux situations d'infertilité étude préliminaire

\author{
S. GAZAL, S. AYCHET \\ UFR de Psychologie - Université de Toulouse - \\ Mirail 5, Allées Antonin Machado - 31058 \\ Toulouse
}

Les innovations technologiques connaissent dans les pays industrialisés un développement rapide dans tous les domaines de la vie sociale.

La mise en cuvre de ces innovations présente pour divers acteurs des avantages et/ou des inconvénients, plus ou moins bien identifiés à différents niveaux (caractérisation, incidence, acteurs notamment). La question se pose donc de manière constante de l'évaluation coût-bénéfice et de la prise de décision.

Dans le domaine de la biologie, l'assistance médicale à la procréation essaie de répondre au désir d'enfant des couples infertiles. Elle repose sur des techniques à évolution rapide, dont les effets délétères possibles sur la femme, la descendance et le couple lui-même ont donné lieu à peu ou pas d'études préalables ou à posteriori. La question se pose donc de la prise en compte des différents aspects du risque (avantages, inconvénients) dans la mise en œuvre par le praticien de l'assistance médicale à la procréation. 
Les recherches en psychosociologie ayant fait apparaître l'existence de corrélations fortes entre représentations et comportements, il a été postulé une relation directe entre la représentation du risque associé à l'assistance médicale à la procréation et le comportement de prescription. Cette hypothèse a été testée par questionnaire en 1998 sur un échantillon de 30 médecins représentatifs des médecins spécialistes de l'AMP de la région Midi-Pyrénées.

L'hypothèse n'a pas été validée $(p=.05)$, à l'exception d'un des quatre indicateurs de comportement retenus (le processus de prise de decision) où la relation est validée à $\mathrm{p}<.05$. En outre, il existe une corrélation forte entre les comportements de prescription et le nombre d'années d'exercice des praticiens (celui-ci étant fortement corrélé à l'âge) $(\mathrm{p}=.01)$.

Nonobstant un certain nombre de critiques d'ordre méthodologique, les comportements de prescription en matière d'AMP ne sont pas globalement corrélés à la représentation des effets délétères qui lui sont potentiellement associés, et le principe de précaution, principe aujourd'hui émergeant sur le plan sociétal ne semble pas intervenir dans la mise en œuvre des techniques d'AMP, notamment par les praticiens dont le nombre d'années d'exercice est inférieur à 10 ans.

\section{$\bullet \bullet \bullet \bullet$}

\section{Apport respectif de la stimulation mécanique et de la chirurgie pour la conservation de spermatozoïdes et l'AMP chez le paraplégique}

\section{N. FRANÇOIS1, F. KABOUB1, J.C. JUILLARD2, J. AUGER2, J.M. KUNSTMANN2}

1Centre Médical pour Adolescents et Jeunes Adultes 77610 Neufmoutiers, 2 CECOS Paris Cochin, Hôpital Cochin, 75014 Paris

Sur le plan génito-sexuel et procréatif, l'aide médicale aux couples dont l'homme est paraplégique a bénéficié des dernières avancées techniques. Il nous a semblé intéressant de faire le point de notre action auprès de 50 hommes paraplégiques ou tétraplégiques qui se sont adressés au CECOS Paris Cochin depuis 1997. Le temps écoulé depuis l'accident ayant engendré la pathologie neurologique était très variable (5 mois- 15 ans, $<2$ ans en moyenne). L'âge moyen des hommes était de 33 ans. Parmi eux, 32 vivaient en couple depuis 5 ans et demi en moyenne. Pour 45 hommes, les données étaient exploitables. En fonction des niveaux de lésion neurologique, la population se décomposait comme suit : 9 tétraplégies complètes - 9 incomplètes, 17 paraplégies complètes au dessus de D10 3 incomplètes, 4 paraplégies complètes D11/L2 - 1 incomplète, 1 paraplégie complète en dessous de $\mathrm{I} .2$ - 1 incomplète. Pour le recueil des spermatozoïdes, 34 sur $45(76 \%)$ ont bénéficié d'un mode de stimulation mécanique (masturbation : 5 , vibromassage : 17 , vibromassage+électro-stimulation : 12) et 11 sur $45(24 \%)$, d'un mode chirurgical. A l'exception d'un cas, le mode chirurgical a été décidé pour tous les hommes concernés après échec du mode mécanique. Pour le cas où la ponction déférentielle a été faite d'emblée, elle s'est avérée blanche. Le recueil ultérieur par vibromassage a permis de recueillir des spermatozoïdes, de réaliser une ICSI suivie de grossesse ayant malheureusement aboutie à une fausse couche. La conservation de spermatozoïdes a été possible dans $40 / 45$ cas (89\%). Dans la sous-population des hommes ayant pu recueillir des spermatozoïdes par un mode mécanique suivi de leur conservation au CECOS, seulement un quart d'entre eux n'avaient pas de projet parental dans un futur proche, la moitié ayant moins de 20 ans. Tous les autres avaient un désir de grossesse. 11 parmi eux ont bénéficié d'une AMP au cours de la période d'étude. Pour 3 couples, la qualité initiale et après décongélation des spermatozoïdes a permis de faire une simple insémination intrautérine : 1 grossesse suivie de naissance a été obtenue. Pour 8 couples, seule l'ICSI était possible. Il y a eu au total 8 tentatives ayant permis 3 grossesses $(37,5 \%$ de grossesse / tentative; 2 fausses couches et une grossesse en cours). Plus généralement, nos données démontraient l'intérêt majeur de l'ICSI chez des patients atteints de lésion neurologique, quel que soit le mode de recueil des spermatozoïdes : pour 11 couples (13 tentatives), 86 ovocytes ont été microinjectés et 53 embryons ont été obtenus (taux de fécondation : $61,6 \%)$. Il y a eu 5 grossesses $(38,5 \%$ grossesses / transfert): 2 grossesses ayant abouti à 2 naissances, une grossesse évolutive et 2 fausses couches. En conclusion, bien que la ponction déférentielle ou la biopsie testiculaire soient actuellement l'approche la plus souvent rapportée pour permettre l'AMP par ICSI chez les paraplégiques, nos résultats indiquent que pour un nombre important d'entre eux, le recueil de spermatozoïdes est possible par des moyens simples mécaniques et non invasifs. Dans ces conditions, la conservation des spermatozoïdes en vue d'AMP est possible et leur utilisation permet d'obtenir des grossesses pour une proportion importante de couples. Notre expé- 
rience chez le paraplégique récent indique l'intérêt d'avoir une approche psychologique adaptée, lui proposant suffisamment tôt une conservation de spermatozoïdes avant que ne surviennent les complications urogénitales.

\section{L'activite fusiogénique des spermatozoïdes humains après irradiation au laser hene à faible énergie (lfe)}

\author{
Y. SOFFER1, A. RAZIEL1, A. UMANSKI1, S. \\ KAUFMAN1, J. LAX2， R. LUBART2, H. BREIT- \\ BART2 \\ 1 Centre d'infertilité masculine, Faculté de \\ Médecine Sackler, Université de Tel Aviv, Centre \\ médical Assaf Harofé, Zerifin \\ 2 Faculté des Sciences Biologiques, Université \\ Barflan. Ramat Gan. Israël
}

INTRODUCTION : Chez les animaux de laboratoire, l'irradiation au LFE améliore le pouvoir fécondant in vitro des spermatozoïdes. Le mécanisme précis de ce phénomène est mal connu, mais il semble que cette irradiation libérerait des radicaux libres actifs sur la cascade biochimique liée à la réaction acrosomique (RA).

BUT DU TRAVAIL : Examiner in vitro les effets de l'irradiation au LFE sur l'activité fusiogénique des spermatozoïdes humains dans l'épreuve de pénétration des ovocytes dépellucidés de hamster (SPA).

MATÉRIEL \& MÉTHODES : Dans un groupe de 43 hommes inféconds, un bilan andrologique a été mis en œuvre incluant des analyses de sperme avec les critères morphologiques de Kruger, la recherche d'auto-anticorps, la RA, le test de l'hémizone (HZA) et l'épreuve du hamster (SPA) renforcée (avec incubation préalable en milieu TEST/jaune d'œuf au froid). Avant l'insémination des ovocytes, les échantillons de sperme ont été divisés en deux portions : l'une irradiée pendant 2 minutes et l'autre non irradiée, pour contrôle. Après 3 heures d'incubation des spermatozoïdes avec les ovocytes dépellucidés, le pourcentage de pénétration ovocytaire des spermatozoïdes irradiés a été comparé à celui des spermatozoïdes de contrôle.

RÉSULTATS : Dans le SPA renforcé, le \% de pénétration des spermatozoïdes humains normaux est
$>30 \%$. Les anticorps étaient sans influence significative sur le SPA. Le SPA et la RA corrélaient bien entre eux, le SPA et le HZA, bien moins. Quant aux effets de l'irradiation, si l'on examine le groupe dans son ensemble, il semble qu'elle n'ait eu aucun effet, le \% de pénétration des spermatozoïdes irradiés ou non était similaire, 49,8 $\pm 39,9$ contre $51,0 \pm 34,9 \%$. A l'analyse cas par cas, l'irradiation était sans effet dans $50 \%$ des cas, accrue dans $25 \%$ et diminuée dans les $25 \%$ restants. Poursuivant cette analyse selon la qualité, " bonne " (SPA $\geq 30 \%$ ) ou "mauvaise" (SPA $<30 \%)$, du sperme de contrôle non irradié, il apparaît qu'avec les "mauvais " spermes $(n=16)$, l'irradiation a été bénéfique dans la moitié des cas avec une pénétration ovocytaire moyenne accrue de 5,5 $\pm 8,9$ à $23,1 \pm 25,2 \%(\mathrm{p}<0.000$ 1 ). Par contre, avec les " bons " spermes $(n=27)$, aucun effet n'a été observé si ce n'est une baisse non significative du taux de pénétration de $76,1 \pm 24,4$ à $67,6 \pm 28 \%$.

CONCLUSION : L'irradiation au LFE a donc un effet sélectif sur l'activité fusiogénique des spermatozoïdes dans les épreuves du hamster. L'irradiation a été bénéfique avec les "mauvais " spermes en renforçant, dans la moitié de ces cas, leur pouvoir fusiogénique. Par contre, cette irradiation a été sans effet, ou peut être même nocive, pour les " bons " spermes. Cette observation mérite des études complémentaires pour confirmation. Il faudrait aussi s'assurer de l'innocuité de ces rayons chez l'homme avant d'envisager quelque application clinique (Ce travail a été soutenu par une subvention du Directeur Scientifique du Ministère de la Santé d'Israël).

Les auto-anticorps IgA et IgG fixés sur les spermatozoïdes perturbent leur attachement à la zone pellucide mais non leur fusion avec l'oolème

Y. SOFFER1, A. RAZIEL 1-2, A. UMANSKI 1, S. KAUFMAN 1-2 S. FRIEDLER 2 L. YOGEV 3 D. STRASSBURGER 1

I - Centre d'infertilité masculine 22 - Unité de FIV, Centre Médical Assaf Harofé, Zerifin. 3 Institut pour l'étude de la.fèrtilité, Maternité Liss, Hôpitaux de Tel Aviv. 1,2,3 Faculté Sackler de Médecine, Université de Tel Aviv, Israël. 
Introduction : Les auto-anticorps IgA et IgG fixés sur les spermatozoïdes peuvent perturber le pouvoir fécondant du sperme dans la fécondation naturelle à deux niveaux d'interactions: 1- au contact de la glaire cervicale, en inhibant la pénétration et l'ascension des spermatozoïdes dans la glaire, 2- au contact de l'œuf, en bloquant les interactions du sperme avec l'œuf et ses membranes. Toutes les techniques d'assistance médicale à la procréation contournent l'obstacle de la glaire cervicale mais non les interactions avec l'ovocyte, à l'exception de l'ICSI.

But de ce travail : Analyser in vitro et d'une manière distincte l'effet des auto-anticorps membranaires IgA et IgG sur les interactions du sperme avec l'œuf aux niveaux de la zone pellucide et de l'oolème à l'aide des épreuves : 1 -d'attache du sperme à la zone pellucide humaine (épreuve de l'hémizone HZA), 2- de fusion sperme-ovocyte (épreuve de pénétration des ovocytes dépellucidés de hamster, SPA).

Matériel \& méthodes : Chez 127 hommes inféconds, un bilan andrologique a été établi incluant des examens de sperme avec les critères morphologiques de Kruger, $(\% \mathrm{FN})$, les test du SpermMar TM pour la recherche d'anticorps IgA et IgG dans le sperme ainsi que les épreuves fonctionnelles de HZA et de SPA. Le HZA et le SPA ont été pratiqués en parallèle sur les mêmes échantillons de sperme. Ces épreuves étant sous l'effet de variables diverses du sperme, une approche multifactorielle a été requise pour dégager les effets distincts des anticorps. Aussi des analyses statistiques à variables uniques et multiples ont-elles été pratiquées.

Résultats : Des anticorps fixés sur les membranes d'un \% significatif de spermatozoïdes ont été trouvés dans $13,8 \%$ des échantillons de sperme pour les IgG, dans $23,1 \%$ pour les IgA et dans $7,4 \%$ pour les deux ensembles. Le taux de HZA était de 56,0 $\pm 37,6$ $\%$ pour tout le groupe, de $59,2 \%$ dans les échantillons sans anticorps et de $22,6 \%$ lorsque les IgA et les IgG étaient tous deux présents $(p<0,04)$. En analyse logistique, les variables significatives de l'équation de HZA étaient, dans l'ordre décroissant, $\%$ FN, IgG, mobilité et IgA. Quant au SPA, il était de 59,4\% $\pm 41,9$ dans tout le groupe, indifféremment de la présence ou de l'absence des IgA et des 1-G $(57,2 \%$ et $60,3 \%$ respectivement). En analyse logistique, les seules variables significatives de l'équation de SPA, étaient la mobilité et le compte des spermatozoïdes.

Conclusion: Le HZA et le SPA intègrent donc des variables spermatiques différentes. Les anticorps IgA et IgG fixés peuvent perturber les interactions du sperme avec l'œuf lors de l'attache à la zone pellucide. Le HZA peut évaluer cet effet délétère. Par contre. aucune dysfonction fusiogénique n'a été détectée à l'épreuve du SPA. Lorsque des anticorps IgA ou IgG sont détectés sur les spermatozoïdes, les épreuves fonctionnelles du sperme sont donc recommandées pour sélectionner la technique d'AMP appropriée (IUI, IVF ou ICSI) au cas.

\section{Intérêt du traitement du syndrome inflam- matoire génital masculin avant AMP ?}

\author{
O. KULSKI1, B. MARTIN-PONT1, I. CEDRIN2, \\ J.N. HUGUES2, J.Ph. WOLF2
}

\section{Service d'Histologie, Embryologie, Cytogénétique, Biologie de la Reproduction \\ 2 Service de Médecine de la Reproduction, Hôpital Jean Verdier, Bondy}

Mots clés : stérilité masculine

Introduction : Certains patients consultant pour une AMP présentent un syndrome inflammatoire caractérisé par une leucocytospermie. Par la production de radicaux libres, elle est souvent associée à une altération des paramètres fonctionnels du sperme (Aitken, Biol Reprod 1998, 59: 1037-46). L'amélioration des qualités spermatiques in vivo par traitement du syndrome inflammatoire n'a toutefois pas été établie. Dans cette étude préliminaire, un anti-inflammatoire (Apranax®) a été prescrit à des patients présentant une leucospermie avec spermoculture négative. L'évolution des paramètres spermatiques et de la leucospermie ainsi que les résultats de l'AMP ont été analysés rétrospectivement (avant et après transfert).

Matériel \& méthodes : 26 patients ont été inclus lors d'une consultation pré-AMP. Les indications de l'AMP étaient : 16 OAT, 6 féminines, 1 idiopathique, 3 mixtes (facteurs masculins et féminins), Il s'agit de patients ayant une leucospermie positive (réaction à la peroxydase) avec une spermoculture négative pour lesquels un traitement par anti-inflammatoire (Apranax® $750 \mathrm{mg} / \mathrm{j}$ ) a été prescrit pour une durée moyenne de 15 jours. $54 \%$ d'entre eux présentaient des antécédents infectieux urogénitaux. Les paramètres spermatiques ont été analysés (critères de l'OMS) avant le traitement, dans le mois suivant son arrêt et à distance ( $\geq 3$ mois).

\section{Résultats :}




\begin{tabular}{|c|c|c|c|c|c|c|c|c|c|c|c|c|c|c|}
\hline & \multicolumn{4}{|c|}{ INITAUX } & \multicolumn{4}{|c|}{ APRES TRAITEMENT } & \multicolumn{4}{|c|}{ A DISTANCE } & \multicolumn{2}{|c|}{$\begin{array}{c}\text { nombre de } \\
\text { grossesses }\end{array}$} \\
\hline & $\operatorname{num}_{10^{\wedge} 6 / \mathrm{ml}}$ & $\underset{\%}{\mathbf{m o b} a+b}$ & vitalite \% & $\begin{array}{c}\text { leuco } \\
10^{\wedge} 6 / \mathrm{ml}\end{array}$ & $\underset{10^{\wedge} 6 / \mathrm{ml}}{\operatorname{num}}$ & $\begin{array}{c}\mathbf{m o b} \mathbf{a}+\mathbf{b} \\
\%\end{array}$ & vitalité \% & $\begin{array}{c}\text { leuco } \\
10^{\wedge} 6 / \mathrm{ml}\end{array}$ & $\underset{10^{\wedge} 6 / \mathrm{ml}}{\text { num }}$ & $\underset{\%}{\operatorname{mob} \mathbf{a}+\mathbf{b}}$ & vitalité \% & $\begin{array}{c}\text { leuco } \\
10^{\wedge} 6 / \mathrm{ml}\end{array}$ & spont. & $\begin{array}{l}\text { après } \\
\text { PMA }\end{array}$ \\
\hline $\begin{array}{c}\text { sperme } \\
\text { OAT } \\
(n=19)\end{array}$ & $40 \pm 55$ & $26 \pm 10$ & $66 \pm 21$ & $\begin{array}{c}\mathbf{5 , 7 8 \pm 5 , 7 2} \\
\mathbf{a , b}\end{array}$ & $30 \pm 39$ & $25 \pm 13$ & $66 \pm 13$ & $\begin{array}{c}1,18 \pm 2,37 \\
a\end{array}$ & $26 \pm 24$ & $28 \pm 16$ & $71 \pm 17$ & $\begin{array}{c}2,63 \pm 3,85 \\
b\end{array}$ & $\underset{(10,5 \%)}{2}$ & $\begin{array}{c}5 \\
(26,3 \%)\end{array}$ \\
\hline $\begin{array}{c}\text { sperme } \\
\text { normal } \\
(n=7)\end{array}$ & $119 \pm 95$ & $46 \pm 11$ & $80 \pm 10$ & $\begin{array}{c}4,31 \pm 5,09 \\
a\end{array}$ & $108 \pm 126$ & $36 \pm 18$ & $75 \pm 12$ & $\begin{array}{c}0,6 \pm 0,64 \\
a\end{array}$ & $118 \pm 112$ & $38 \pm 10$ & $68 \pm 11$ & $4,25 \pm 6,82$ & $\begin{array}{c}1 \\
(14,3 \%)\end{array}$ & $\stackrel{3}{3}$ \\
\hline
\end{tabular}

\section{Evolution des paramètres spermatiques sous anti-inflammatoire :}

$a$ : significativement différent $p<0,001$

b : p $<0,05$

La leucospermie diminue après le traitement de façon significative mais réaugmente modérément à distance. Il en est de même pour le rapport leucospermie/ concentration spermatique. Il a été noté parfois une augmentation paradoxale et transitoire de la leucospermie due à la baisse initiale des sécrétions des granulocytes.

20 techniques d'AMP (2 IIU, 7 FIV, 10 ICSI, 1 stimulation ovarienne) ont été réalisées. Trois grossesses spontanées (11,5\% des patients) pour 2 OAT et 1 indication féminine (endométriose) sont survenues et 8 après AMP (5 ICSI, 2 FIV, 1 stimulation ovarienne) ( $30,7 \%$ des patients) dont 5 évolutives.

Conclusion : Le traitement anti-inflammatoire fait chuter la leucospermie. En l'absence de traitement étiologique et/ou du fait de l'insuffisance du traitement elle réapparaît à distance surtout pour les spermes normaux. La survenue de 3 grossesses spontanées dans un délai court suggère un effet bénéfique du traitement. Celui-ci doit être confirmé par une étude prospective randomisée.

\section{A l'ère de l'injection intra-cytoplasmique de spermatozoïde (ICSI nouvel algorithme dans l'évaluation et le traitement des azoosper- mies.}

\section{A. MAILLETTE, M. THABET \\ Pavillon St François d'Assise (CHUQ), Quebec, Canada}

Introduction : L'azoospermie est retrouvée chez environ $20 \%$ des patients consultant pour infertili- té. Cette étude rétrospective visait premièrement à caractériser les causes d'azoospermie et préciser lors de l'évaluation quels patients pourraient bénéficier des nouvelles techniques de reproduction (ICSI) . Deuxièmement, nous voulions évaluer la pertinence des marqueurs épididymaires, de la FSH et de la biopsie testiculaire dans l'investigation d'une azoospermie fonctionnelle (AF).

Matériel et Méthodes : Nous avons procédé à une étude rétrospective de 250 patients vus à la clinique d'infertilité du pavillon SFA entre 1984 et 1998 chez qui une azoospermie a été diagnostiquée. Les patients furent ensuite classés selon leur étiologie respective ; 56 azoospermies obstructives (AO), 168 fonctionnelles, 17 mixtes et 9 de cause indéterminée. Pour tous les patients, nous avons analysé le volume testiculaire, le spermogramme (volume, $\mathrm{PH}$ ), le bilan hormonal, les marqueurs épididymaires et les biopsies testiculaires.

Résultats : Parmi les 168 patients avec AF les étiologies étaient les suivantes: $62 \%$ idiopathique, $10 \%$ post-cryptorchidie, $8 \%$ post-varicocèle, $6 \%$ post-chirurgie antérieure (torsion), $6 \%$ secondaire aux gonadotoxines (chimio), 6\% associée au Klinefelter et $2 \%$ postinfection. Pour l'ensemble des patients, 91 biopsies testiculaires furent effectuées et cellesci s'avéraient normales chez $70 \%$ des AO comparativement à seulement 7\% des AF. En présence d'AF, l'arrêt de maturation, l'aplasie des cellules germinales et l'hypospermatogénèse étaient retrouvés dans environ $33 \%$ des cas respectivement. Nous avons ensuite classé les causes d'AF selon la découverte histologique. La FSH était élevée ( $>2 \mathrm{X}$ la normale) chez $69 \%$ des AF comparativement à seulement 5\% des AO. L'alphaglucosidase et la L-carnitine étaient abaissées plus significativement chez les AO. Pour l'ensemble des patients, l'insémination par donneur a été proposée chez $76 \%$ d'entre eux. Avec l'arrivée de l'ICSI, nous avons établi un nouvel algorithme décisionnel afin de mieux cerner quels patients pourraient bénéficier d'une telle option.

Conclusion : Nous avons démontré que les marqueurs épididymaires et la FSH s'avèrent toujours 
essentiels dans le diagnostic d'une azoospermie. Par cette étude, nous avons évalué la pertinence de la biopsie testiculaire en cas d'azoospermie fonctionnelle et déterminé quels patients pourraient être dirigés vers l'ICSI (environ $80 \%$ d'entre eux).

\section{STERILITE}

\section{Profil immunologique des patients consultant pour hypofertilité}

\author{
M. AJINA, N. CHAKROUN, H. HICHRI, \\ M. MEHDI. A.SAAD \\ Laboratoire de Cytogénétique et Biologie de la \\ Reproduction-CHU F Hached de Sousse - Tunisie
}

négatifs, les conjoints présentaient dans tous les cas des ACAS négatifs dans le plasma séminal. Cette corrélation intra-conjugale est très probablement en rapport avec des antécédents infectieux communs. Devant ce pourcentage élevé d'ACAS positifs, chez les couples hypofertiles, il sera nécessaire d'élargir les indications de recherche d'anticorps anti-spermatozoïdes dans les milieux biologiques afin de cerner les étiologies de ces hypofertilités d'une part et de mieux prendre en charge ces couples d'autre part, nécessitant parfois l'usage de techniques spéciales de l'Assistance Médicale à la Procréation.

\section{Pesticides et fertilité : Résultats d'une recherche épidémiologique menée aupres des viticulteurs alsaciens}

3 à $10 \%$ des couples infertiles présentent une stérilité d'origine auto-immune, ceci justifie la recherche des auto anticorps dirigés contre les antigènes de surface des spermatozoïdes dans le liquide séminal, le sérum et la glaire. Notre étude porte sur 62 couples ayant bénéficié de la recherche d'anticorps anti-spermatozoïdes (ACAS). Cette analyse a été réalisée par spermagglutination dans le plasma séminal chez tous les patients et dans le sérum et/ou la glaire cervicale chez certains d'entre eux. Cette technique permet de mettre en évidence des anticorps libres dans ces milieux. Le Mar test permet de rechercher des anticorps fixés sur la membrane du spermatozoïde. Il a été fait chez 8 patients. $60 \%$ des patients avaient des spermatozoïdes agglutinés lors du spermogramme, $13 \%$ d'entre eux avaient des ACAS positifs dans le plasma séminal. Les résultats du Mar test concordent parfaitement avec ceux de la spermagglutination. Dans le sérum, chez les hommes les ACAS étaient positifs dans $57 \%$ des cas ( 4 cas positifs parmi 7). Dans la glaire cervicale, les demandes d'ACAS étaient peu nombreuses, 2 cas sur 4 étaient positifs (50\%).

Il ressort de notre étude que le pourcentage d'hommes ayant des anticorps antispermatozoïdes libres dans le plasma séminal est relativement proche de celui décrit dans la littérature. Quant au sérum ce pourcentage est élevé, ceci serait dû au petit nombre de cas sélectionnés. Chez $50 \%$ des femmes ayant des ACAS positifs, les conjoints présentaient des ACAS positifs dans le plasma séminal et dans le sérum. Chez les femmes ayant des ACAS

\section{A. CLAVERT1 B. DUCOT1 A. SCHWEITZER1 Michèle WAGNER1, P. THONNEAU 2 \\ 1 CECOS Alsace, Strasbourg 2 Groupe de recherche en fertilité humaine / INSERM, Service d'Urologie - Andrologie, Hôpital La Grave, 31052 Toulouse Cedex, France.}

Afin d'évaluer les effets de l'utilisation des pesticides sur le délai nécessaire à concevoir et sur les caractéristiques spermatiques, nous avons mené une recherche épidémiologique (rétrospective) et biologique (prospective) chez des viticulteurs alsaciens, suivis dans le cadre de la Mutualité Sociale Agricole (MSA). Pour la partie rétrospective la comparaison de 65 viticulteurs exposés aux pesticides aux 98 viticulteurs non exposés, n'a pas mis en évidence de différence significative quant à la durée mise par les couples pour obtenir une conception. Pour la partie prospective, nous avons pu comparer les principales caractéristiques spermatiques avant et après l'exposition aux pesticides chez 25 viticulteurs. De faibles diminutions, non statistiquement significatives, de la concentration et de la mobilité ont été notées après la saison d'utilisation des pesticides.

Ces résultats encourageants quant à l'absence d'effets délétères des pesticides observables sur la fonction reproductrice masculine doivent toutefois être considérés avec prudence, étant donné le faible nombre d'individus inclus dans le volet prospectif et aussi la multiplicité et les difficultés d'identification des expositions. 


\section{CANCER}

\section{Risque de deuxième cancer non germinal après traitement d'un séminome testiculaire de stade I - II}

\section{LATORZEFF"1, M. SOULIE 2, F. BERTHIER3, C. CHEVREAU 4, J.M. BACHAUD1 \\ 1- Département de Radiothérapie, Institut Claudius Regaud, Toulouse, France 2-Service de Chirurgie Urologique, CHU Rangueil, Toulouse, France 3-Registre des Cancers du Tarn, Albi, France 4-Département d'Oncologie Médicale, Institut Claudius Regaud, Toulouse, France}

BUT : Mesurer l'incidence des seconds cancers d'origine non germinale (SCNG) chez les patients traités pour un séminome testiculaire de stade I II.

MATÉRIEL ET MÉTHODE : L'étude porte sur 131 patients évaluables traités à l'Institut Claudius Regaud entre 1970 et 1990 . Les modalités thérapeutiques, incluant le traitement de rattrapage de 6 patients ayant présenté une rechute, sont les suivantes: irradiation sous-diaphragmatique (IsousD) seule ou sous et sus diaphragmatique (Isous $\mathrm{D} \pm$ IssusD) et, d'autre part, irradiation et chimiothérapie (ICI).

Dans 55 cas irradiation sous et sus-diaphragmatique (IsousD \pm IssusD) dans 64 cas, irradiation et chimiothérapie (ICI) dans 12 cas. Cinq patients ont été perdus de vue 4 mois à 14 ans après le primo traitement (suivi moyen : 11 ans). L'incidence cumulative des SCNG a été comparée à l'incidence globale des cancers dans la population masculine du même âge établie grâce au Registre des Cancers du Tarn. Le risque relatif a été exprimé en Rapport d'Incidence Standardisé (SIR).

RÉSULTATS : L'incidence cumulée des SCNG est de $10,7 \%$ (14/131 patients). Le SIR est égal à 2,81 $(\mathrm{p}<0,001)$ et augmente avec la durée du suivi. Le SIR est significativement augmenté chez 64 patients traités par IsousD \pm lssusD $(\mathrm{SIR}=3,08, \mathrm{p}$ $0,002)$ mais non chez 55 patients traités par IsousD seule ( $\mathrm{SIR}=0,62, \mathrm{p}=0,8$ ). Les 12 patients traités par IC ont un SIR de 26,2 ( $p<0,001)$. Trois des 4 patients ayant présenté une hémopathie maligne appartiennent au groupe IC

CONCLUSION Le risque de SCNG est augmenté après IsousD-IsusD. Après IsousD seule, le risque de SCNG n'est pas majoré au terme d'un suivi médian de 6 ans, mais ce délai est trop court pour pouvoir tirer une conclusion définitive. Le risque de SCNG et particulièrement d'hémopathie semble augmenté par l'association de radiothérapie et de chimiothérapie

\section{Intérét de l'échographie scrotale chez les patients infertiles aux antécédents de cryp- torchidie: étude prospective de 147 cas}

\section{J.P. GRAZIANA, J.M. RIGOT, Ph. MAHE, E. GOULLET, F. SAINT, L*.LEMAITRE, E.MAZEMAN}

Service d'urologie, "'service de radiologie Ouest CHRU Lille

OBJECTIF : Si l'étude échographique scrotale systématique chez l'homme infertile reste controversée par certains, il nous a paru intéressant d'apprécier son apport chez les patients aux antécédents de cryptorchidie et consultant pour infertilité.

MATÉRIEL ET MÉTHODES : Entre janvier 1994 et avril 1999, 928 patients consultant pour infertilité ont été suivis de façon prospective. 147 patients $(15,8 \%)$, d'âge moyen de 30,1 ans $(20-45)$ ont été traités pour cryptorchidie bilatérale chez : 91 patients ( 51 azoospermies, 40 OATS), ct unilatérale chez 56 patients (28 azoospermies, 28 OATS). Ils ont tous bénéficié d'une échographie scrotale (sonde superficielle de haute fréquence : 7.5 à $10 \mathrm{~Hz}$ ), étudiant le volume testiculaire (hypotrophie définie pour un volume $<15 \mathrm{ml}$ ) et sa structure (voir tableau).

CONCLUSION : Un antécédent de cryptorchidie chez un homme consultant pour infertilité impose la réalisation systématique d'une échographie scrotale. Elle permet le diagnostic de tumeurs infracliniques $(4,7 \%)$ et révèle des anomalies de structure (microcalcifications $8,8 \%$, plages hypoéchogènes $22,4 \%)$, nécessitant une surveillance échographique dans certains cas. 


$\begin{array}{lllll} & \text { Bilatérale } & \text { Unilatérale } & \text { Totale } & \text { Série contrôle } \\ \text { Patients } & 91 & 45 & 147 & 609 \\ \text { Volume normal } & 17 & 9 \text { (controlat. 25) } & 26 & 388 \\ \text { Hypotrophie } & 74 & 47 \text { (controlat. 31) } & 121 & 221 \\ \text { Microcalcifications } & 7 & 4 \text { (controlat. 2) } & 13 & 15 \\ \text { Nodule hypoéchogène } & 4 & 3 & 7 & 9 \\ \text { Plage hétérogène } & 19 & 12 \text { (controlat. 2) } & 33 & 7 \\ \text { Kyste } & 1 & 1 & 2 & 2\end{array}$

\section{SEXOLOGIE}

\section{Traitement pharmacologique des troubles de l'éjaculation. \\ Mise au point et analyse critique de la littérature}

\section{DELAVIERRE, H. IBRAHIM, M. PENEAU \\ Service Urologie-Andrologie, CHR La Source, Orléans}

Les troubles de l'éjaculation, 2ème motif de consultation andrologique après la dysérection, regroupent l'éjaculation prématurée et l'anéjaculation, cette dernière comprenant l'éjaculation sèche, l'éjaculation rétrograde, l'éjaculation baveuse et l'anorgasmie. Des traitements pharmacologiques sont proposés dans la prise en charge de ces pathologies.

\section{Ejaculation prématurée}

Produits disponibles

- Alpha-bloquants

- Clomipramine (antidépresseur imipraminique, 30 à $60 \mathrm{mg}$ par jour ou $25 \mathrm{mg} 12$ à 24 heures avant la relation sexuelle)

- Antidépresseurs sérotoninergiques

Indications place de choix dans certains cas, le plus souvent appoint (ou attente) d'une thérapie plus globale.

. Résultats " satisfaisants " dans environ $50 \%$ des cas avec les alpha-bloquants et dans 70 à $100 \%$ des cas avec les antidépresseurs.
Inconvénients : effets secondaires, risque (mal évalué) de récidive à l'arrêt du traitement

Critique de la littérature : certes il existe des études randomisées contrôlées contre placebo mais ... souvent peu de cas, expression des résultats non standardisée, durée de suivi courte et devenir à long terme méconnu

\section{Anejaculations}

Produits disponibles et indications

- Anéjaculations psychologiques et neuropathies périphériques

Parasympathicolytiques per-os (Bromphéniramine, Imipramine)

Sympathomimétiques alpha (Phényl-propanolamine per-os, Midodrine per-os ou IMIIV)

- Myélopathies

Parasympathomimétiques (Esérine sous cutanée ou IM)

Midodrine

\section{Critique de la littérature}

le seul domaine étudié et évalué est celui de l'homme paraplégique.

\section{Conclusion}

Les traitements pharmacologiques des troubles de l'éjaculation sont mal connus et plutôt mal évalués sauf cas particuliers. Aucun des produits cités ne dispose d'une AMM sauf la Midodrine pour certaines éjaculations rétrogrades et uniquement dans sa forme injectable. 